\title{
Haemodynamic evaluation of pulmonary hypertension
}

\author{
D. Chemla*, V. Castelain*, P. Hervé ${ }^{\#}$, Y. Lecarpentier*, S. Brimioulle
}

\begin{abstract}
Haemodynamic evaluation of pulmonary hypertension. D. Chemla, V. Castelain, P. Hervé, Y. Lecarpentier, S. Brimioulle. C)ERS Journals Ltd 2002.

ABSTRACT: Pulmonary hypertension is characterised by the chronic elevation of pulmonary artery pressure (PAP) and pulmonary vascular resistance (PVR) leading to right ventricular enlargement and hypertrophy. Pulmonary hypertension may result from respiratory and cardiac diseases, the most severe forms occurring in thromboembolic and primary pulmonary hypertension.

Pulmonary hypertension is most often defined as a mean PAP $>25 \mathrm{mmHg}$ at rest or $>30 \mathbf{m m H g}$ during exercise, the pressure being measured invasively with a pulmonary artery catheter. Doppler echocardiography allows serial, noninvasive follow-up of PAPs and right heart function. When the adaptive mechanisms of right ventricular dilatation and hypertrophy cannot compensate for the haemodynamic burden, right heart failure occurs and is associated with poor prognosis.

The haemodynamic profile is the major determinant of prognosis. In both primary and secondary pulmonary hypertension, special attention must be paid to the assessment of pulmonary vascular resistance index (PVRI), right heart function and pulmonary vasodilatory reserve.

Recent studies have stressed the prognostic values of exercise capacity (6-min walk test), right atrial pressure, stroke index and vasodilator challenge responses, as well as an interest in new imaging techniques and natriuretic peptide determinations. Overall, careful haemodynamic evaluation may optimise new diagnostic and therapeutic strategies in pulmonary hypertension.

Eur Respir J 2002; 20: 1314-1331.
\end{abstract}

\begin{abstract}
*Dept of Cardiac and Respiratory Physiology, Bicêtre Hospital, Faculty of Medicine, University of Paris XI, Le Kremlin-Bicêtre and, ${ }^{\#}$ Dept of Thoracic and Vascular Surgery, Marie Lannelongue Hospital, le PlessisRobinson, France. "Intensive care unit, Erasme Hospital, Brussels, Belgium.
\end{abstract}

Correspondence: D. Chemla, Service EFCR, Broca 7, Hôpital de Bicêtre, 78 rue du Général Leclerc, 94275 Le Kremlin Bicêtre, Paris, France.

Fax: 33145213778

E-mail: denis.chemla@bct.ap-hop-paris.fr

Keywords: Cor pulmonale pulmonary hypertension pulmonary vasodilatory reserve right atrial pressure

right ventricle

walk test

Received: July 292002

Accepted after revision: August 52002
The normal adult pulmonary vascular bed is a low-pressure, low-resistance, highly distensible system, and is capable of accommodating large increases in blood flow with minimal elevations of PAP. Pulmonary hypertension $(\mathrm{PH})$ is characterised by the chronic elevation of PAP and PVR leading to right ventricular enlargement and hypertrophy [1-8]. At first, PAP is normal at rest but rises abnormally high with exercise. In more evolved stages, PH occurs at rest (fig. 1). When the adaptive mechanisms of right ventricular dilatation and hypertrophy cannot compensate for the haemodynamic burden, right heart failure occurs and is associated with poor prognosis. $\mathrm{PH}$ may result from respiratory and cardiac diseases, the most severe forms occurring in thromboembolic $\mathrm{PH}$ and primary PH. The World Health Organization (WHO) has recently proposed a revised diagnostic classification (table 1) [1].

$\mathrm{PH}$ is most often defined as a mean PAP $>25 \mathrm{mmHg}$ at rest or $>30 \mathrm{mmHg}$ during exercise, the PAP being measured invasively with a pulmonary artery (PA) catheter. However, there is no clear consensus as to what level of PAP constitutes PH [1-8]. Proposed upper normal values for mean PAP range $18-25 \mathrm{mmHg}$ at rest. Other definitions of $\mathrm{PH}$ have been used, which either include a systolic PAP $>30 \mathrm{mmHg}$, or rely on the level of PVR. During exercise, a mean PAP threshold $>30 \mathrm{mmHg}$ may apply in healthy older subjects. Doppler echocardiography allows the noninvasive assessment of PAP, and systolic PAP is most commonly used. Proposed upper normal values range $40-50 \mathrm{mmHg}$ at rest, which correspond to a tricuspid regurgitant velocity of $3.0-3.5 \mathrm{~m} \cdot \mathrm{s}^{-1}$ [1]. However, Doppler-derived PAP critically depends upon age, body mass index (BMI) and right atrial pressure (RAP).

$\mathrm{PH}$ may be identified during testing of symptomatic patients, during screening of patients at risk (table 1), or it may be discovered incidentally [1-8]. PH is a rare condition and its symptoms are nonspecific, which

Previous articles in this Series: No. 1: Humbert M, Trembath RC. Genetics of pulmonary hypertension: from bench to bedside. Eur Respir $J$ 2002; 20: 741-749. No. 2: Galiè N, Manes A, Branzi A. The new clinical trials on pharmacological treatment in pulmonary arterial hypertension. Eur Respir J 2002; 20: 1037-1049. 


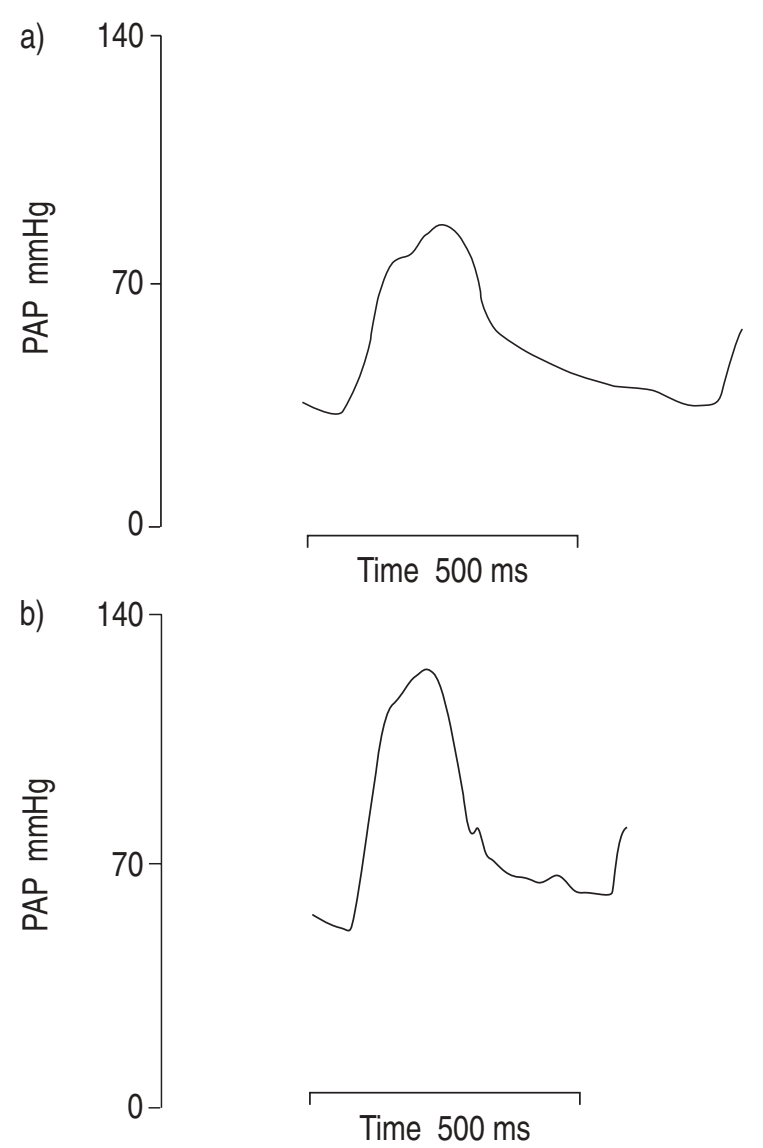

Fig. 1.- Typical pulmonary artery curve tracing a) at rest and b) during exercise (workload $45 \mathrm{~W}$ ) in a patient with primary pulmonary hypertension. The noise is minimal with the use of a high-fidelity pressure-measuring catheter. PAP: pulmonary artery pressure.

explains why the diagnosis may be delayed. In the National Institutes of Health $(\mathrm{NIH})$ primary $\mathrm{PH}$ registry, the mean interval from onset of symptoms to diagnosis was 2 yrs [7]. The most common presenting symptom is dyspnoea, followed by fatigue, syncope or near syncope and chest pain. The clinical presentation of PH critically depends upon its cause, but it is not within the scope of the present review to detail this point. The general diagnostic approach includes physical examination, exercise capacity testing (6-min walk test), chest radiograph, electrocardiography, laboratory tests (blood tests, arterial blood gases, pulmonary function tests), noninvasive cardiac and pulmonary imaging and cardiac catheterisation [1-8]. Cardiac catheterisation allows for the precise establishment of the diagnosis and the type of $\mathrm{PH}$, the severity of the disease, the consequences on right heart function, and the amount of pulmonary vasodilatation in reserve. Echocardiography is especially valuable in the serial assessment of PAP and right and left heart function.

The early initiation of treatments at a time when dynamic or reversible pathogenic mechanisms are present may increase the likelihood of a successful treatment outcome [1]. A screening transthoracic echocardiogram is therefore recommended in asymptomatic patients with scleroderma or liver disease/
Table 1.-World Health Organization diagnostic classification

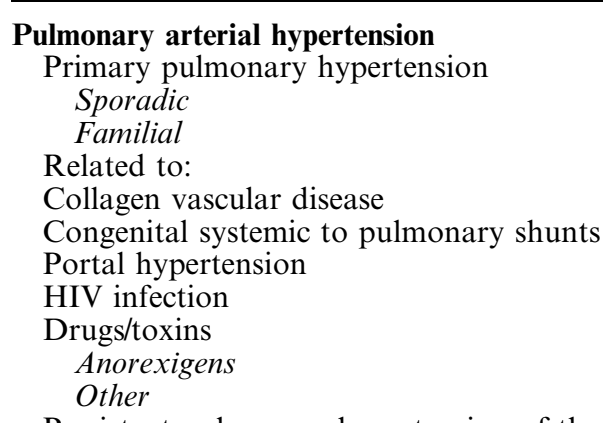

Persistent pulmonary hypertension of the newborn Other

Pulmonary venous hypertension

Left-sided atrial or ventricular heart disease

Left-sided valvular heart disease

Extrinsic compression of central pulmonary veins Fibrosing mediastinitis Adenopathyltumours

Pulmonary veno-occlusive disease Other

Pulmonary hypertension associated with disorders of the respiratory system and/or hypoxaemia

Chronic obstructive pulmonary disease

Interstitial lung disease

Sleep-disordered breathing

Alveolar hypoventilation disorders

Chronic exposure to high altitude

Neonatal lung disease

Alveolar-capillary dysplasia

Other

Pulmonary hypertension due to chronic thrombotic and/or embolic disease

Thromboembolic obstruction of proximal pulmonary arteries

Obstruction of distal pulmonary arteries Pulmonary embolism (thrombus, tumour, ova andlor parasites, foreign material)

In situ thrombosis

Sickle cell disease

Pulmonary hypertension due to disorders directly affecting the pulmonary vasculature

Inflammatory

Schistosomiasis

Sarcoidosis

Other

Pulmonary capillary haemangiomatosis

Although this clinical classification is primarily concerned with causes and thus prevention and treatment, the classification is in keeping with the pathological characterisation of pulmonary hypertensive states; Pulmonary hypertension $(\mathrm{PH})$ that results from identifiable causes (secondary $\mathrm{PH}$ ) is far more common than pulmonary hypertension with no apparent cause (primary PH); HIV: human immunodeficiency virus.

portal hypertension evaluated for liver transplantation, and in asymptomatic subjects with a family history of primary PH (first degree relatives). Recent studies have identified mutations in the genes which encode for receptor members of the transforming growth factor- $\beta$ family in familial (and sporadic) primary $\mathrm{PH}$, and in $\mathrm{PH}$ associated with hereditary haemorrhagic telangiectasia, and this provides promising perspectives to genetic testing in $\mathrm{PH}$ [9]. 


\section{Pathophysiology of haemodynamic changes in pulmonary hypertension}

\section{Pulmonary artery pressure}

The pressure drop across the pulmonary circulation (i.e. the driving pressure) is often referred to as the transpulmonary pressure gradient (TPG):

$$
\mathrm{TPG}=\text { mean } \mathrm{PAP}-\text { downstream pressure }
$$

In analogy with the electric Ohm's law, TPG equals PVR times cardiac output [10-13]:

mean $\mathrm{PAP}-$ downstream pressure $=$

$$
\text { PVR } \times \text { cardiac output }
$$

The equation can be rewritten as follows:

$$
\begin{aligned}
& \text { mean } \mathrm{PAP}=(\mathrm{PVR} \times \text { cardiac output })+ \\
& \text { downstream pressure }
\end{aligned}
$$

The normal pulmonary circulation is a low resistance circuit, with little or no resting vascular tone, and the most important factors influencing mean PAP are hydrostatic pressure, intra-alveolar pressure, left atrial pressure and alveolar gases.

$\mathrm{PH}$ is most often defined as a mean PAP $>25 \mathrm{mmHg}$ at rest. According to the mechanistic classification [12], increases in mean PAP may be passive (as a result of increased downstream pressure), hyperkinetic (as a result of increased cardiac output through the lungs) or due to increased PVR resulting from changes in the pulmonary circulation itself. Granted that various hypertensive mechanisms can work jointly, two forms of $\mathrm{PH}$ have been defined. Postcapillary PH (or pulmonary venous hypertension) is a passive form characterised by an increased downstream pressure $\geqslant$ $15 \mathrm{mmHg}$ and a normal TPG. Precapillary PH (or pulmonary arterial hypertension) is characterised by a normal downstream pressure $(<15 \mathrm{mmHg})$. TPG is increased because of increased cardiac output or increased PVR. Increases in PVR are due to a significant reduction in the area of the distal (mainly resistive) and/or proximal (mainly capacitive) PAs. This classification illustrates the crucial role of cardiac catheterisation in determining not only the mean PAP and cardiac output but also the downstream pressure.

\section{Pulmonary vascular resistance}

The PVR is used to characterise $\mathrm{PH}$ in a more restricted sense and to quantify abnormalities of the pulmonary vasculature according to the following equation:

$$
\begin{aligned}
& \mathrm{PVR}=(\text { mean } \mathrm{PAP}-\text { downstream pressure }) / \\
& \text { cardiac output }
\end{aligned}
$$

PVR is expressed in Wood units $=(1 \mathrm{WU}=1 \mathrm{mmHg}$. $\min \cdot \mathrm{L}^{-1}=80$ dyne $\cdot \mathrm{s} \cdot \mathrm{cm}^{-5}$ ).

The PVR is mainly related to the geometry of small distal resistive pulmonary arterioles. According to Poiseuille's law, PVR is inversely related to the fourth power of arterial radius. PVR is therefore considered to mainly reflect the functional status of pulmonary vascular endothelium/smooth muscle cell coupled system [10-13]. PVR is also positively related to blood viscosity and may be influenced by changes in perivascular alveolar and pleural pressure.

Pressure is independent of the size of the system, and PAP from various subjects can therefore be compared without the need to take into account potential differences in their body size. Conversely, variables such as volume are proportional to the size of the system. For comparative purposes, the PVRI is therefore defined as the pressure drop across the circuit divided by cardiac index (in $\mathrm{WU} \cdot \mathrm{m}^{2}$ or in $\mathrm{mmHg} \cdot \mathrm{L}^{-1} \cdot \mathrm{min} \cdot \mathrm{m}^{2}$ or in dyne $\cdot \mathrm{s} \cdot \mathrm{cm}^{-5} \cdot \mathrm{m}^{2}$ ). In patients with high BMI, the use of PVR instead of PVRI has been responsible for significant underestimation of $\mathrm{PH}$, and for the occurrence of haemodynamic and respiratory failure following heart transplantation. The use of PVRI must be recommended in studies evaluating new therapeutic strategies in $\mathrm{PH}$.

Pulmonary arterial hypertension results from three main elements: vascular wall remodelling, thrombosis and vasoconstriction [8]. The increases in PVRI may be fixed and/or potentially reversible. Arterial obstruction, obliteration and remodelling are responsible for the fixed component, while active increases in vascular tone are responsible for the reversible component, which may account for $>50 \%$ PVRI. The pulmonary vascular tone results from a complex interplay between the pulmonary endothelium, smooth muscle cells, extracellular matrix, and circulating blood cells and blood components. In PH, the dysfunction of pulmonary arterial endothelium plays a key role, whether due to external stimulus (e.g. shear stress, shear rate, hypoxia, acidosis) or to the disease process itself (e.g. primary $\mathrm{PH})$.

Hypoxia, acidosis, endothelin, nitric oxide, thrombosis, neurohormones

Alveolar hypoxia is a major stimulus leading to pulmonary vasoconstriction either via a direct pressor effect or by causing mediators to discharge. Acidosis leads to pulmonary vasoconstriction as well as acting synergistically with hypoxia. Hypoxic vasoconstriction is the main mechanism explaining mild and moderate degrees of $\mathrm{PH}$ in patients with chronic obstructive pulmonary disease (COPD), in whom severe chronic long-standing hypoxia is observed. An oxygen tension in arterial blood $\left(\mathrm{Pa}_{\mathrm{a}} \mathrm{O}_{2}\right)<7.98 \mathrm{kPa}(<60 \mathrm{mmHg})$ and a carbon dioxide tension in arterial blood $>5.32 \mathrm{kPa}$ $(>40 \mathrm{mmHg}$ ) are thought to be accurate thresholds for the development of PH in COPD [14]. A recent study has shown that mean PAP inversely correlated with arterial $\mathrm{Pa}_{\mathrm{a}} \mathrm{O}_{2}$, forced expiratory volume in one second $(\%)$ and single-breath carbon monoxide diffusion capacity $(\%)$ and directly correlated with pulmonary wedge pressure in patients with severe emphysema [15]. Surprisingly, all factors but $\mathrm{Pa}_{\mathrm{a}} \mathrm{O}_{2}$ remained significant determinants of mean PAP when multiple regression analysis was used. Although 
methodological explanations may be discussed, this result suggests that factors other than hypoxia are involved in $\mathrm{PH}$ of patients with severe emphysema [15]. In COPD patients with mild-to-moderate hypoxia, the progression of PAP is very slow $\left(+0.4 \mathrm{mmHg} \cdot \mathrm{yr}^{-1}\right)$ and only initial values of resting and exercise mean PAP are independently related to the subsequent development of $\mathrm{PH}$ [16]. In patients with primary $\mathrm{PH}$ or chronic pulmonary thromboembolism, hypocapnia is commonly observed; the $P \mathrm{a}, \mathrm{O}_{2}$ may be within normal limits or only slightly decreased at rest, while hypoxaemia is observed with exercise $[17,18]$. Rightto-left shunt is the main mechanism of hypoxia in the Eisenmenger syndrome. Severe hypoventilation is associated with hypoxia and may lead to $\mathrm{PH}$, particularly if there is associated acidosis. This may explain the $\mathrm{PH}$ observed in the setting of the obesity-hypoventilation Pickwickian syndrome and in a number of muscular disorders [6]. In patients with $\mathrm{PH}$, high resting PAP and PVRI values increase further following exercise or acute hypoxaemia (e.g. rapid eye movement (REM) sleep or respiratory failure in patients with COPD). It is important to prevent, diagnose and treat pulmonary infections in $\mathrm{PH}$ patients. Altitudes $>1500 \mathrm{~m}$ must be avoided without supplemental oxygen, and altitudes $>3000$ m must be discouraged.

The pathogenic role of endogenous endothelin-1 has been stressed, together with impaired synthesis of vasorelaxant nitric oxide, and this may have therapeutic implications $[19,20]$. $\mathrm{PH}$ is associated with activation of the endothelin system, which has potent vasoconstrictive and mitogen properties. Thrombosis can play a part in the pathophysiology of the disease, as attested to by the platelet activation, disturbances of various steps of the coagulation cascade and abnormal thrombolysis described in PH [21]. Primary or secondary endothelial dysfunction increase the risk of thrombotic events. Dilated right heart chambers, sluggish pulmonary blood flow and sedentary lifestyle also increase this risk. Adrenergic overdrive may precipitate right ventricle (RV) failure and high plasma noradrenaline is associated with increased mortality in patients with primary $\mathrm{PH}$, suggesting that the level of sympathetic activation relates to the severity of the disease [22].

\section{Other precipitating factors}

Changes in the rheological blood properties may aggravate PH. Erythrocytosis may be secondary to hypoxia, and is potentially responsible for increased blood viscosity and changes in erythrocyte deformability. PH may be aggravated by increases in cardiac output in the setting of hyperadrenergic states, anaemia and hyperthyroidism. Decreased diastolic time (e.g. tachycardia) or the loss of atrial contribution to left ventricle (LV) filling (e.g. atrial fibrillation) tend to increase left atrial pressure and thus may also aggravate $\mathrm{PH}$. Finally, permanent $\mathrm{PH}$ is self-aggravating, as it favours several local pathological processes, including the remodelling of small distal arteries and the loss of the elastic properties of proximal arteries, thus leading to a vicious circle.

\section{The right ventricle in pulmonary hypertension}

\section{Right ventricular function}

RV has a complex geometry and is characterised by a crescentic shape and a thin wall [23]. The crista supraventricularis divides the RV into inflow and outflow regions. Inflow (sinus), which is located posterior and inferior, has a greater fibre shortening and is the effective flow generator, pumping $>85 \%$ of the stroke volume. Outflow (conus), which is located anterior and superior, is a resistive and pulsatile conduit with a limited ejection capacity. RV contraction proceeds from the sinus to the conus according to a peristaltic movement. Right ventricular output equals heart rate times stroke volume. For a given stroke volume, RV output increases when heart rate increases (chronotropic reserve). For a given heart rate, RV output increases when RV end-diastolic volume increases (preload reserve) or when RV end-systolic volume decreases. The RV end-systolic volume decrease can be due to increased inotropy (inotropic reserve) or to decreased RV end-systolic pressure. The latter mechanism may be observed in some healthy subjects during exercise (distensibility, recruitment) and in a subgroup of $\mathrm{PH}$ patients following vasodilators (pulmonary vasodilatory reserve).

The thin-walled, highly compliant RV can accommodate with high volumes at physiological pressures (e.g. exercise), thanks to its marked preload-dependence and RV-LV interdependence [23]. However, the RV is unable to face an acute increase in PVRI, and works inefficiently when confronted with $\mathrm{PH}$ [24]. Thus, unlike the LV, the RV performance is markedly afterload-dependent. In PH patients, the use of preload reserve (Frank-Starling's mechanism) helps preserve RV function. Furthermore, according to Laplace's law, an increase in afterload can be offset by an increase in RV wall thickness (RV hypertrophy), and this normalises RV wall stress and myocardial oxygen consumption. There is a linear correlation between RV mass and free wall area, indicating that an increase in afterload causes RV enlargement with both dilatation and hypertrophy [25]. Chronic cor pulmonale is defined as dilatation and hypertrophy of the RV secondary to $\mathrm{PH}$ caused by diseases of the pulmonary parenchyma and/or pulmonary vascular system between the origins of the main PA and the entry of the pulmonary veins into the left atrium [26, 27].

Right ventricular ejection fraction (RVEF) is much more sensitive to changes in ventricular afterload than LV ejection fraction [28]. The RVEF has been found to augment with exercise in healthy subjects given the decreased PVRI and increased contractility of the RV free wall $[29,30]$. In patients with $\mathrm{PH}$, the decreases in RVEF are not indicative of decreased RV contractility but mainly reflect increased afterload [31]. In primary $\mathrm{PH}$ studied at rest, cardiac function is characterised by RV systolic overload due to PH and diastolic overload with tricuspid regurgitation (TR), whereas the $\mathrm{LV}$ is subject to diastolic underloading and reduced compliance $[32,33]$. With exercise, RV systolic performance further declines with a reduction in stroke volume and ejection fraction, and consequently heart 
rate becomes the mechanism by which cardiac output increases.

\section{Right ventricular failure}

$\mathrm{RV}$ failure may be related to the natural evolution of the disease or to acute exacerbation of PH (e.g. following acute hypoxaemia). In both primary $\mathrm{PH}$ and thromboembolic $\mathrm{PH}$, the main cause of death is RV failure [1-8]. COPD is the most common pulmonary disease that culminates in RV dysfunction $[24,34]$. An autopsy study suggests that cor pulmonale is found in $40 \%$ COPD patients [35]. Cor pulmonale is mainly observed in "blue bloaters" who develop a low cardiac output profile and severe hypoxaemia and erythrocytosis resulting in PH. Conversely, "pink puffers" exhibit less severe hypoxaemia, decreased cardiac output and increased arteriovenous oxygen content difference, and cor pulmonale is less likely to develop despite increased PVRI [24]. In a number of COPD patients, peripheral oedema may not always be explained by RV failure, but rather relate to hypercapnia, acidosis and increased sympathetic and reninangiotensin-aldosterone activities, and the related changes in renal haemodynamics and redistribution of body water [36].

When pulmonary arterial impedance is chronically increased, RV function and output are preserved thanks to RV dilation and hypertrophy, increased inotropy and faster heart rate. Both increased impedance and increases in RV size and annulus diameter lead to TR, which further compromise RV function. Decreased $\mathrm{RV}$ function is observed when the limits of cardiac reserves are reached or when significant RV-LV interdependence or chronic RV ischaemia are present (fig. 2). The mechanisms for RV ischaemia include increased pressure work leading to increased myocardial oxygen consumption; reduced systemic pressure leading to decreases in the coronary perfusion driving pressure; and higher sensitivity to hypoxia and reduced vasodilatory reserve of the hypertrophied $\mathrm{RV}[23,34]$. In patients with end-stage RV failure, the

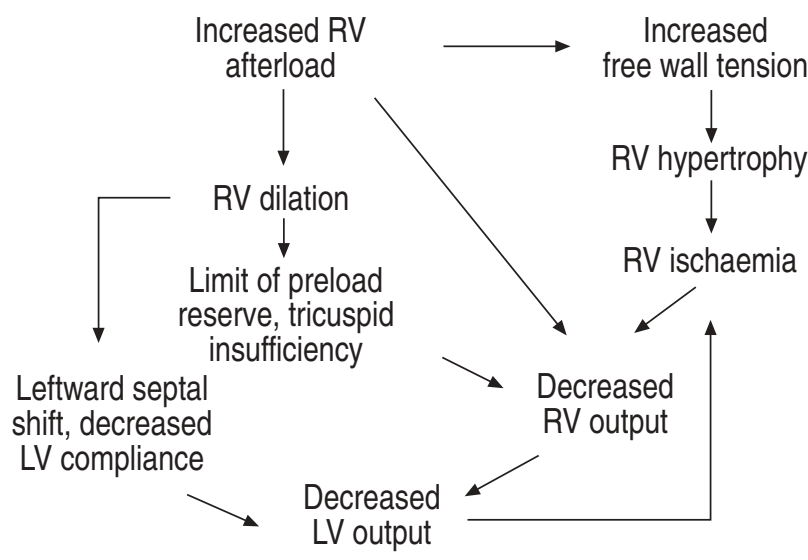

Fig. 2.-Main pathophysiological factors involved in right and left heart failure in patients with pulmonary hypertension. RV: right ventricle; LV: left ventricle. maintenance of a sufficiently high systemic pressure is of major importance to prevent RV ischaemia, and this may require high doses of vasoconstrictive agents (e.g. noradrenaline).

Numerous factors may precipitate RV failure [23, 24, 34]. Factors related to preload include impaired venous return (e.g. mechanical ventilation), decreased preload reserve (e.g. hypovolaemia) and mechanical limitation (e.g. effusive pericarditis). Factors related to afterload include acute load increases (although pulmonary embolism-related RV failure is observed only for acute systolic pressure $>60-70 \mathrm{mmHg}$ ), increased pulsatile load (e.g. proximal obstruction with markedly increased pulse wave reflections), and factors related to transpulmonary pressure, lung compliance and mechanical ventilation. Major tricuspid valve insufficiency may precipitate RV failure, and the anatomical and functional status of the tricuspid valve has a key role in preserved RV function. Other factors potentially precipitating $\mathrm{RV}$ failure are decreased inotropy, RV ischaemia, REM sleep and obstructive sleep apnoea syndrome. The deleterious role of hypoxia and neurohormonal factors has also been demonstrated.

\section{Therapeutic implications}

The main goals in the prevention and treatment of RV failure include: 1) reducing RV afterload by decreasing PVRI; 2) limiting pulmonary vasoconstriction (e.g. prevention of hypoxaemia); 3) optimising RV preload; and 4) preserving coronary perfusion through maintenance of systemic blood pressure. Other strategies may depend upon the cause of $\mathrm{PH}$ (e.g. recipient selection for preventing acute RV failure following cardiac transplantation) [37].

\section{Exercise capacity}

During exercise, the pulmonary vascular bed of normal subjects shows a minimal rise in PAP despite the doubling or tripling of cardiac output, thanks to the substantial reserve of pulmonary circulation. The fall in PVRI reflects passive distension of compliant small vessels and/or recruitment of additional vessels in the superior portions of the lung [10-13, 38].

According to the New York Heart Association (NYHA) functional classification, symptoms may be caused by ordinary physical activity (Class II), less than ordinary activity (Class III) or may even be present at rest (Class IV) in $\mathrm{PH}$ patients [1-8]. Recent guidelines focus on the rational management of patients without any limitation of their physical activity (Class I) [1]. It must be remembered that clinical symptoms poorly correlate with resting mean PAP [39]. The degree of preservation of systolic performance of the RV is the main factor governing the clinical presentation.

In patients with primary $\mathrm{PH}$, impaired cardiac reserve during exercise is reflected in reduced peak $\mathrm{O}_{2}$ uptake $\left(V^{\prime} \mathrm{O}_{2}\right)[40,41]$. The NYHA functional class best correlates with $\%$ predicted peak $V^{\prime} \mathrm{O}_{2}$, which 
allows a precise grading of the severity of the disease [42]. A reduction of the anaerobic threshold also appears to be an independent marker of the disease severity. The $\mathrm{O}_{2}$ pulse can be calculated as the $V^{\prime} \mathrm{O}_{2}$ divided by heart rate ratio, and equals the product of stroke volume times the $\mathrm{O}_{2}$ content difference between arterial and mixed venous blood. The progressively decreasing peak $\mathrm{O}_{2}$ pulse reflects a progressive reduction (or inadequate increase) in peak stroke volume paralleling disease severity [42]. Patients with primary $\mathrm{PH}$ exhibit hyperventilatory response to exercise, i.e. impaired ventilatory efficiency, as attested to by the increased slope relating minute ventilation to carbon dioxide output $\left(V^{\prime} \mathrm{E} / V^{\prime} \mathrm{CO}_{2}\right)[42]$. However, the fitting of a linear slope is somewhat arbitrary in patients with primary $\mathrm{PH}$ as the ventilation of underperfused alveoli causes an increase in dead space ventilation, and also because a significant number of patients may have a patent foramen ovale, both conditions leading to nonlinearities of the $V^{\prime} E-$ $V^{\prime} \mathrm{CO}_{2}$ relationship. Finally, in patients with primary $\mathrm{PH}$, exercise stroke volume response is related to resting haemodynamics, namely diastolic PAP (inversely), PVRI (inversely) and pulse wave reflection factor (directly) [43].

Maximal exercise testing must be prohibited in $\mathrm{PH}$ patients, as syncope and sudden death have been reported. Submaximal exercise testing may be less unpleasant for the patient and is more representative of daily life activity [44]. In primary $\mathrm{PH}$, Мгунмото et al. [39] have reported that the distance walked in 6 min was decreased in proportion to the severity of the NYHA functional class, and was strongly correlated with peak $V^{\prime} \mathrm{O}_{2}$ and oxygen pulse. The distance walked in 6 min has a strong, independent association with mortality and patients walking $<332 \mathrm{~m}$ had a significantly lower survival than those walking farther [45]. In primary $\mathrm{PH}$ patients performing the 6-min walk test, a distance $\leqslant 300 \mathrm{~m}$ and reduction in arterial oxygen saturation $\left(\mathrm{Sa}_{\mathrm{a}} \mathrm{O}_{2}\right)$ at maximal distance $\geqslant 10 \%$ increased mortality risk by 2.4 and 2.9 , respectively [18]. The distance walked in 6 min may serve as a safe prognostic indicator throughout the survey. Finally, in patients with advanced heart failure, $\mathrm{RVEF} \geqslant 0.35$ at rest and during exercise is a more powerful predictor of survival than $V^{\prime} \mathrm{O}_{2}[46]$.

\section{Cardiac catheterisation: standard procedures}

Right heart and PA catheterisation remains the gold standard used to establish the diagnosis and the type of PH. This procedure helps quantify the severity of the disease, the consequences on right heart function and the amount of vasodilatation in reserve. Furthermore, the haemodynamic profile is the major determinant of prognosis in PH. Initial studies have reported that catheterisation carries an increased risk in patients with $\mathrm{PH}$, which is why it is important to ensure that catheterisation is performed by an experienced team, familiar with $\mathrm{PH}$ patients. The prevention of vasovagal reaction and pain, and extreme caution in Class IV patients, are needed.
There were no deaths during catheterisation procedures in the NIH registry study $(n=187)$ [40].

\section{Pulmonary artery pressure}

Cardiovascular textbooks indicate a 9-19 $\mathrm{mmHg}$ range for normal mean PAP at sea level [47, 48]. In resting healthy subjects aged 6-45 yrs, mean PAP remains constant at $14 \pm 3 \mathrm{mmHg}[2,4]$. Although mean PAP increases slightly to $16 \pm 3 \mathrm{mmHg}$ between $60-83 \mathrm{yrs}$, it is generally agreed that mean PAP is little influenced by age in healthy subjects [2, 4, 49, 50]. There is no clear consensus as to what resting mean PAP level constitutes PH. Pressure values $>18 \mathrm{mmHg}$ $[4,51], 20 \mathrm{mmHg}[5,6,38,52]$ and $25 \mathrm{mmHg}[5]$ have been proposed, the latter cut-off value being the one most often used in recent clinical trials. Other definitions of $\mathrm{PH}$ include a systolic PAP $>30 \mathrm{mmHg}$ at rest and a mean $\mathrm{PAP}>30 \mathrm{mmHg}$ on exercise $[5,51$, 52]. The cause and type of $\mathrm{PH}$ also influence the haemodynamic profile, which is the major determinant of PH prognosis. For example, $\mathrm{PH}$ of mild (mean $\mathrm{PAP}=25-35 \mathrm{mmHg}$ ) and moderate (mean PAP $=35$ $45 \mathrm{mmHg}$ ) intensity are more common in $\mathrm{PH}$ secondary to cardiac diseases or COPD, whereas severe $\mathrm{PH}$ (mean PAP $\geqslant 45 \mathrm{mmHg}$ ) is generally found in primary $\mathrm{PH}$ and in chronic pulmonary thromboembolism [1-8].

Pulmonary occlusion pressure, pulmonary vascular resistance index, total peripheral resistance index and pulmonary hypertension classification

Downstream pressure is approximated on the basis of the pulmonary occlusion pressure $(P \mathrm{~A}, \mathrm{op})$. PA,op provides a more accurate estimate of left atrial pressure than mean PA capillary wedge pressure (PA,wp), which overestimates left atrial pressure when pulmonary venous resistance is increased [53, 54]. In normoxic healthy subjects, the difference between mean PAP and $P$ A,wp is $5-9 \mathrm{mmHg}$ [4]. The $P$ A,op value allows diagnosis of the type of $\mathrm{PH}$, namely pulmonary venous $(P \mathrm{~A}$, op $\geqslant 15 \mathrm{mmHg})$ or arterial $(P \mathrm{~A}, \mathrm{op}<15 \mathrm{mmHg})$ hypertension. Measurements of mean PAP, $P$ A,op and cardiac index allow the calculation of PVRI according to standard formula. Unlike mean PAP, PVRI increases significantly with age $[4,49,50]$. The upper limit for PVRI (in $\mathrm{mmHg} \cdot \mathrm{L}^{-1} \cdot \mathrm{min} \cdot \mathrm{m}^{2}$ ) in normal subjects increases from $\sim 2.8$ (6-10 yrs) to $3.2(32-45 \mathrm{yrs})$ to $4.6(60-83$ yrs $)[2,4]$. There is no consensus as to what resting PVRI level constitutes $\mathrm{PH}$, and threshold values ranging from $3-6 \mathrm{mmHg} \cdot \mathrm{L}^{-1} \cdot \mathrm{min} \cdot \mathrm{m}^{2}$ have been used previously. Although it has often been reported that an accurate $P$ A,op may be unobtainable in patients with severe $\mathrm{PH}$, this is rarely the case in experienced teams. Total peripheral resistance (TPR; equal to mean PAP/cardiac output) and total peripheral resistance index are calculated in cases where reliable $P A$,op recordings are not obtained.

A PVR threshold value may be included in the diagnostic criteria of some forms of $\mathrm{PH}$, e.g. portopulmonary hypertension (POPH) [55-57]. POPH can be defined as a pulmonary arterial hypertension 
associated with portal hypertension with or without hepatic disease. A moderate increase in mean PAP $(25-35 \mathrm{mmHg})$ is observed in up to $20 \%$ of patients with cirrhosis and portal hypertension. This passive increase in mean PAP, which relates to increased cardiac output and/or blood volume, is associated with near normal PVRI (i.e. minimum pulmonary vascular remodelling) and normal or increased $P$ A,op (pulmonary venous hypertension). A severe pulmonary arterial hypertension with extensive pulmonary vascular remodelling and elevated PVR is more rarely observed in patients with portal hypertension. This latter condition represents the entity of POPH and is associated with poor outcome. To distinguish between these two forms of $\mathrm{PH}$, the following POPH criteria have been proposed $[55,56]: 1)$ mean PAP $>25 \mathrm{mmHg}$ at rest; 2) PVR $>120$ dyne $\cdot \mathrm{s}^{\cdot} \mathrm{cm}^{-5}$; and 3) $\mathrm{PA}$,op $<$ $15 \mathrm{mmHg}$.

Cardiac index, evaluation of intracardiac shunt, venous oxygen saturation, uric acid

The determination of cardiac index is essential for the diagnostic work-up and follow-up programme in patients with $\mathrm{PH}$. The thermodilution technique is used in the vast majority of PH centres. In patients with severe $\mathrm{PH}$, a recent study indicates that thermodilution was equally accurate to the Fick method (the gold standard technique) over a broad range of cardiac output values $\left(1.7-7.8 \mathrm{~L} \cdot \mathrm{min}^{-1}\right.$ ) [58]. Although conflicting results have been published, the agreement between the two methods was not affected by the severity of tricuspid regurgitation [58]. In most cases of $\mathrm{PH}$, the accuracy of the thermodilution technique is acceptable. However, in case of intracardiac shunt, as in the patients with patent foramen ovale, the thermodilution technique is inappropriate. Only the Fick method, with measurement of pulmonary venous $\mathrm{O}_{2}$ content is able to measure pulmonary blood flow.

Oximetry (i.e. diagnostic saturation run and computation of the pulmonary to systemic flow ratio) is required to exclude intracardiac shunting. Further investigations (dye dilution curves and angiography) may also be required although they do not intrinsically belong to the standard evaluation of $\mathrm{PH}$. The high pulmonary blood flow-related hyperkinetic component of $\mathrm{PH}$ is often associated with vasoconstriction (reactive component) and arterial remodelling (obstructive/obliterative component). The prevalence of patent foramen ovale in PH is similar to the normal population, and this finding provides no detectable influence on resting haemodynamics or exercise tolerance in patients with $\mathrm{PH}$ [59].

Assuming normal haemoglobin content and normal $\mathrm{Sa}_{\mathrm{a}} \mathrm{O}_{2}$, the fall in mixed venous oxygen saturation $\left(S_{\mathrm{V}}, \mathrm{O}_{2}\right)$ is a reliable indicator of the fall in cardiac index, as predicted from the Fick equation. It is important to compare $S_{\mathrm{v}, \mathrm{O}_{2}}$ values between subjects at similar, optimal $\mathrm{Sa}_{\mathrm{a}} \mathrm{O}_{2}$, and this may require supplemental oxygen. Decreased $S_{\mathrm{v}}, \mathrm{O}_{2}$ has been found to be a strong predictor of poor outcome in some studies [7, 60] while others do not document such a link [40]. $\mathrm{PH}$ patients with an $\mathrm{S}_{\mathrm{v}, \mathrm{O}_{2}}<60 \%$ are more likely to respond to prostaglandin treatment [61]. An increase in $S_{\mathrm{v}}, \mathrm{O}_{2}$ under treatment may indicate an improved cardiac index and a decreased RV afterload both during vasodilator challenge [62] and long-term therapy [63].

Tissue hypoperfusion and hypoxia resulting from reduced cardiac output induce both overproduction and impaired excretion of uric acid, leading to increased serum levels of uric acid in patients with severe primary PH [64, 65]. Serum uric acid negatively correlates with cardiac output and positively correlates with TPR [64].

\section{Right heart function}

In the setting of $\mathrm{PH}$, decreased cardiac index and elevated mean RAP and RV end-diastolic pressure indicate RV dysfunction. Although threshold values may depend upon each laboratory and upon the type of catheter used, mean RAP $<6 \mathrm{mmHg}$ and RV enddiastolic pressure $<8 \mathrm{mmHg}$ are generally considered normal values $[47,48]$. A mean $\mathrm{RAP} \geqslant 8 \mathrm{mmHg}$ and RV end-diastolic pressure $\geqslant 12 \mathrm{mmHg}$ are abnormally high values highly suggestive of $\mathrm{RV}$ failure. The decreased compliance of the hypertrophied RV also contributes to increase RV end-diastolic pressure. In the case of typical TR, RAP rises throughout $\mathrm{RV}$ systole, with pressure regurgitation waves. In early stages of $\mathrm{PH}$, the RV contractility is increased and the peak rate of RV pressure rise may be increased by up to 10 times the normal value [66]. Analysis of RV waveform in more severe forms of the disease reveals RV systolic dysfunction with depressed upstroke and delayed relaxation.

\section{Pulmonary arterial hypertension}

Isolated arterial hypertension is characterised by a $P$ A,op $<15 \mathrm{mmHg}$ and a diastolic PAP minus $P$ A,op gradient $>10 \mathrm{mmHg}$. Major increases in PAP and PVRI are found in thromboembolic and primary PH. Vascular obstruction/obliteration is typically observed in thromboembolic [67] and primary $\mathrm{PH}[8,68]$. In chronic pulmonary thromboembolism, the thrombi follow an aberrant path of organisation and recanalisation, leaving endothelialised residua that narrow and stiffen major (main, lobar or segmental) PAs, i.e. elastic arteries. In primary $\mathrm{PH}$, pulmonary obstructive vasculopathy involves distal, medium-to-small sized muscular (resistive) arteries. In the latter case, both a fixed obstructive component and a reactive component (increased vascular tone) contribute to PH. In COPD patients, hypoxia-induced vasoconstriction plays a major role in producing $\mathrm{PH}$, and destruction of the pulmonary vascular bed is also involved. The increased resistance to flow through the pulmonary vascular bed may be due to several other diseases (table 1), including the Eisenmenger syndrome. In this syndrome, the left-to-right shunts, mainly post-tricuspid shunts, lead to irreversible $\mathrm{PH}$ at systemic level which subsequently cause the shunt to be reversed [6]. 


\section{Pulmonary venous hypertension}

Increased resistance to pulmonary blood flow downstream leads to passive PH, with elevation of PAP but no significant elevation of PVRI. In patients with increased left heart filling pressure, pulmonary venous hypertension is characterised by a $P$ A,op $\geqslant 15 \mathrm{mmHg}$. Although the diastolic PAP minus $P$ A,op gradient is $<10 \mathrm{mmHg}$, diastolic PAP must not be used as a surrogate of downstream pressure. In a recent study, diastolic PAP was $>5 \mathrm{mmHg}$ higher than $P$ A,wp in $21 \%$ and $57 \%$ of cardiac patients with mean PAP of 21-40 $\mathrm{mmHg}$ and $>40 \mathrm{mmHg}$, respectively [69]. Acute increases in pulmonary flow (e.g. exercise) worsens pulmonary venous hypertension when blood flow through the left atria or LV filling are impeded. Additional reactive vasoconstriction and vascular remodelling may occur, especially in cases where left heart filling pressure is markedly and durably increased. A decrease in left heart filling pressure usually reverses both the passive and vasoreactive components of $\mathrm{PH}$ and therefore tends to normalise PAP.

A $P$ A,op $>15 \mathrm{mmHg}$ may be observed together with a diastolic PAP minus $P$ A,op gradient $>10 \mathrm{mmHg}$. In such combined venous and arterial PH, PAP does not normalise following the alleviation of the high downstream pressure, given the fixed arterial component of PH (e.g. evolved mitral stenosis). In these patients, high levels of PVRI are sometimes referred to as the "second stenosis" and may have both deleterious effects (by increasing the strain put on the RV), and protective effects (by limiting RV output and thus the occurrence of episodes of pulmonary oedema) [23]. Finally, some catheterisation findings may be evocative of pulmonary veno-occlusive disease (e.g. the failure to obtain a $P$ A,wp tracing) [70].

\section{Vasodilator testing}

The potentially treatable vasoconstrictive component may be found in numerous forms of $\mathrm{PH}$ and thus must be sought during catheterisation by acute reversibility testing [71]. The vasodilator challenge response is the first step of the algorithm currently used for the management of primary PH [8]. Vasodilator challenge must be performed by an experienced team and requires intensive care equipment. Indeed, druginduced systemic hypotension (e.g. with prostacyclin) may reduce $\mathrm{RV}$ coronary blood flow and result in acute RV ischaemia. There is no advantage in testing more than one drug. The most specific short-acting vasodilator for pulmonary vessels is inhaled nitric oxide (iNO), the maximal effect being obtained after $5-10 \mathrm{~min}$ at the dose of 10 parts per million (ppm). Since iNO has no systemic effects, the resulting drop in PVRI reliably indicates the amount of pulmonary vasodilatation in reserve [72]. Other vasodilators have been proposed, including i.v. iloprost (epoprostenol sodium), a prostacyclin analogue with fewer systemic effects, and i.v. adenosine.

There is no clear consensus as to what criteria may indicate beneficial response to vasodilator challenge. Because mean PAP and PVRI may vary spontaneously by $\leqslant 20-25 \%$, measurements must be performed after stabilisation, and only changes greater than spontaneous haemodynamic variability must be taken into account. A significant response to vasodilator testing is currently defined as a drop in mean PAP or PVRI by $>20 \%[60,73-76]$. Other definitions include a $>30 \%$ threshold $[62,77,78]$ or a reduction in mean PAP $>10 \mathrm{mmHg}$ [1], or an increase in cardiac index by $\geqslant 30 \%$ [61].

In most studies on primary $\mathrm{PH}$, the proportion of responders to vasodilators ranges from $12-40 \%$ depending on the patient's age, RV function, the cause of hypertension and the protocol used [79]. The absence of pulmonary vasodilatory reserve has been associated with a poor outcome [60,71, 80-82]. A decrease in PVRI by $\geqslant 20 \%$ predicts good response to long-term vasodilator therapy with calcium channel blockers [83]. BARST et al [74] found it safer to prescribe longterm chronic calcium channel blocker therapy only in patients exhibiting a decrease in PVR of $\geqslant 50 \%$.

In $\mathrm{PH}$ patients evaluated for cardiac transplantation, some authors have defined irreversible (or fixed) $\mathrm{PH}$ as those patients who, after provocative vasodilator therapy, have either a PVR $\geqslant 4 \mathrm{mmHg} \cdot \mathrm{L}^{-1} \cdot \mathrm{min}$, a PVRI $\geqslant 6 \mathrm{mmHg} \cdot \mathrm{L}^{-1} \cdot \mathrm{min} \cdot \mathrm{m}^{2}$, a systolic PAP $\geqslant 60 \mathrm{mmHg}$ or a tranpulmonary pressure gradient $\geqslant 15 \mathrm{mmHg}$ [37]. Patients with reversible (or reactive) haemodynamics have better prognosis than patients with irreversible PH. Serial aggressive sequences of long-term inotropic support followed by provocative vasodilatory testings may convert fixed $\mathrm{PH}$ into the reactive category and condition the pulmonary vasculature into a maximally dilated state ("vasodilator conditioning") [37].

\section{Cardiac catheterisation: recent issues}

\section{Pulmonary resistance partitioning}

More insight into the pulmonary circulation can be obtained by estimating the effective pulmonary capillary pressure, in order to discriminate between increases in arterial resistance and in venous resistance. Clinically, capillary pressure is computed by analysing the PAP decay after single arterial occlusion by an intravascular balloon [53, 84, 85] (fig. 3). Recent studies have confirmed a predominant increase in arterial resistance in thrombo-embolic disease, a significant increase in arterial but also in venous resistance in primary $\mathrm{PH}$, and the expected major increase in venous resistance in pulmonary venoocclusive hypertension $[38,53]$.

\section{Pulmonary arterial pressurelflow relationship}

The transposition of Poiseuille's law to pulmonary circulation rests on the main assumptions that the PAP-flow relationship is linear, and that the PAP is equal to downstream pressure at zero flow. The first assumption appears valid in both normal and diseased pulmonary circulation over physiological ranges of flows [38, 53, 86, 87] (fig. 4). Initial work by JANICKI 


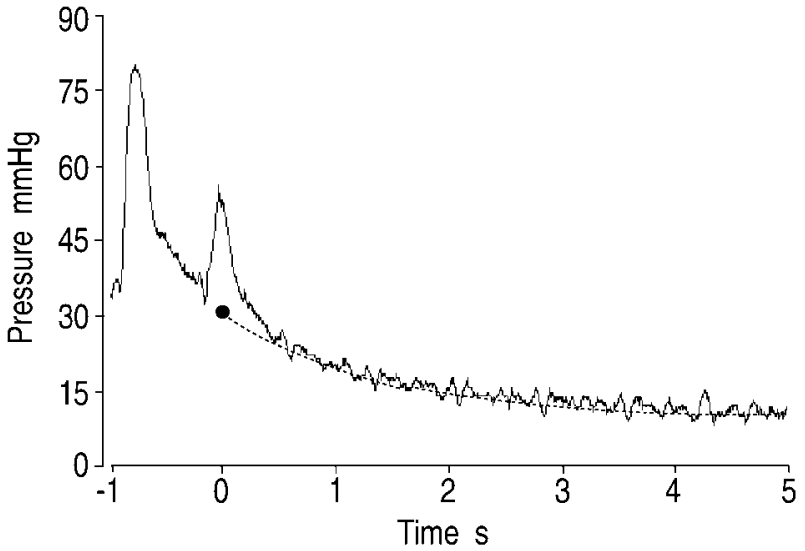

Fig. 3.-Typical pulmonary artery occlusion recording used to estimate pulmonary capillary pressure (PCP) and the arterial segment of pulmonary vascular resistance (PVRa) in a patient with pulmonary arterial hypertension [16, 89]. A balloon-tipped flow-directed pulmonary catheter was used. PCP (time=0) was computed from the exponential pressure decay by fitting the data between the moment of occlusion of the balloon of the pulmonary catheter and the stabilisation of the pressure level (pulmonary artery occlusion pressure $(P \mathrm{~A}, \mathrm{op}))$ (dotted line). Mean pulmonary artery pressure $=53 \mathrm{mmHg} ; \quad P$ A,op=13 mmHg; $\quad \mathrm{PCP}=31 \mathrm{mmHg}$; $\mathrm{PVRa}=55 \%$ PVR. $\bigcirc \mathrm{PCP}=30 \mathrm{mmHg}$.

et al. [38] suggested that the second assumption was also valid in normal subjects and in the majority of $\mathrm{PH}$ patients. However, in one fourth of the $\mathrm{PH}$ patients in this study, the average closure pressure exceeded PA,wp [38]. More recent experiments have shown that the pressure axis intercept of the mean PA pressure/flow relationship (i.e. the closing pressure) is higher than $P \mathrm{~A}$,op or left atrial pressure in primary $\mathrm{PH}$ $[53,88]$ (fig. 3). In such conditions, a change in PVRI can be interpreted unequivocally only when cardiac

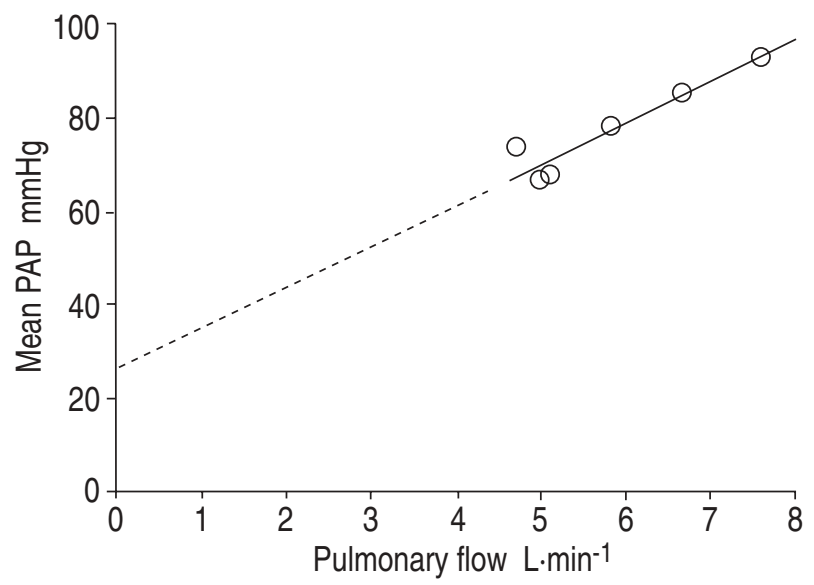

Fig. 4. - Mean pulmonary artery pressure (PAP)-flow plots ( $n=6$, )) obtained at rest ( 1 plot), during exercise (4 plots, the workload being increased stepwise to $15,30,45$ and $60 \mathrm{~W}$ ) and during recovery (1 plot) in a patient with primary pulmonary hypertension. High-fidelity PAP measuring catheter was used. Pulmonary artery occlusion pressure $(P \mathrm{~A}, \mathrm{op})=12 \mathrm{mmHg}$ at rest and $18 \mathrm{mmHg}$ at peak exercise. The solid line indicates the regression line applied to the data set and the dotted line indicates the pressure-flow relationship extrapolated below the lowest data point. The pressure intercept at zero-flow (closure pressure= $27 \mathrm{mmHg}$ ) was markedly higher than $P$ A,op. output remains unchanged, or when driving pressure and cardiac output change in opposite direction.

Increased driving pressure with decreased pulmonary flow attests to vasoconstriction, while decreased driving pressure with increased pulmonary flow attests to vasodilatation (fig. 5). Other haemodynamic patterns are not easy to interpret [86] (fig. 6). For example, increases in PAP and decreases in PVRI (e.g. after drug administration) can result from increases in cardiac output without any modification in pulmonary vascular tone. Therefore, the determination of multipoint mean PAP-flow plots provides

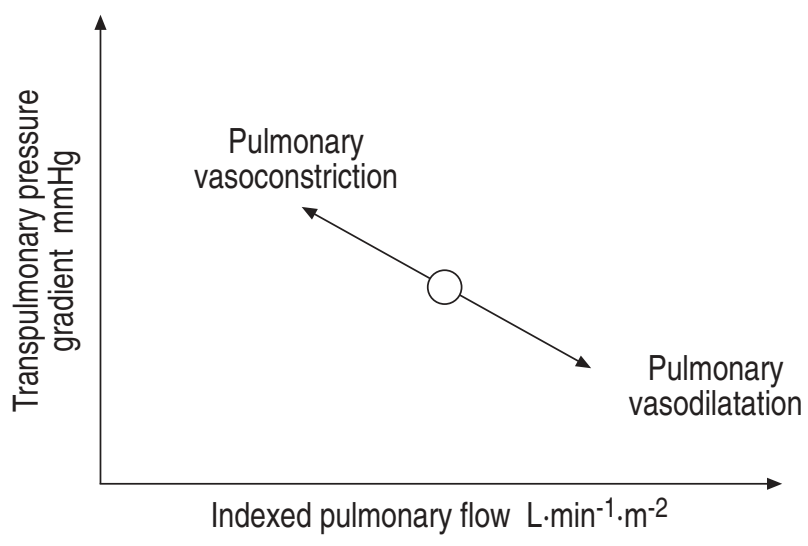

Fig. 5.-Schematic of pressure-flow changes typical of pulmonary vasoconstriction and vasodilatation. Pulmonary vasoconstriction is diagnosed on the basis of transpulmonary pressure gradient versus pulmonary flow relationship showing increased driving pressure with decreased flow. Pulmonary vasodilatation is diagnosed on the basis of transpulmonary pressure gradient versus pulmonary flow relationship showing decreased driving pressure with increased flow.

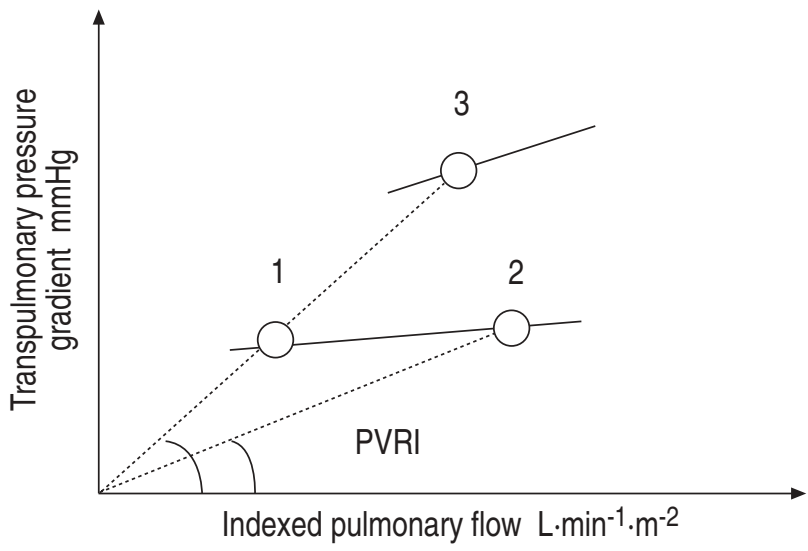

Fig. 6.-Schematic of complex pressure-flow changes. Current problems may be encountered in interpreting single measurement of indexed pulmonary vascular resistance (PVRI) calculated as the transpulmonary pressure gradient over indexed pulmonary flow ratio (slope of the dotted line). The solid line indicates the multipoint pulmonary artery (PA) pressure-flow relationship, with closure pressure greater than PA occlusion pressure. From 1 to 2, PVRI decreases while functional state of the pulmonary circulation (as described by the transpulmonary pressure gradientpulmonary flow relationship) remains essentially unchanged. From 1 to 3 , PVRI is unchanged while the increased slope of the relationships attests to worsening of pulmonary hypertension. 
more accurate insight into the nature of increased PVRI [38, 53, 86-89].

Thus, in PH, both closing pressure and the capillary pressure determined from the analysis of the PAP decay curve after balloon occlusion are increased [86, 88]. The main site of increased resistance may be at the periphery of the pulmonary arterial tree, and this is possibly a cause of increased closing pressure [86]. Greater venous involvement than previously assumed has also been suggested recently [88]. In patients with $\mathrm{PH}$, recent data using two-point curves have suggested that exercise is associated with some pulmonary vasoconstrictive effect, while dobutamine at doses $\leqslant 10 \mathrm{mcg} \cdot \mathrm{kg}^{-1} \cdot \mathrm{min}^{-1}$ allows cardiac output to increase without affecting pulmonary vascular tone [86, 89]. Finally, in patients with primary $\mathrm{PH}$, mean PAP-flow plots have indicated that the improvement in exercise tolerance seen after 6 weeks of prostacyclin therapy may be ascribable to a decrease in incremental PVR during exercise through a vasodilator effect [87].

\section{Pulmonary vascular impedance}

The pulmonary vascular impedance (PVZ) is a frequency-dependent function encompassing information about resistive, capacitive and inertial components of vascular hydraulic load, as well as the extent of pulse wave reflection [10,43]. Few studies have been performed in patients, due to a requirement for simultaneous recordings of high-fidelity pressure and flow signals. Results are reported as spectra of PVZ amplitude and PVZ phase versus frequency. PVZ spectra in patients with $\mathrm{PH}$ demonstrate increases of both the steady component (increased resistance) and oscillatory component (elevated PA characteristic impedance and increased pulse wave reflection) of hydraulic load [43]. Decomposition of pressure and flow into forward and backward components show an increased amplitude and early arrival of the reflected pressure wave, contributing to unfavourable loading of the still-ejecting RV [43]. A preliminary report has suggested that high characteristic impedance could predict better than PVR the occurrence of severe right ventricular failure after cardiac transplantation [90].

\section{Pressure pulsatility}

For a given stroke volume, the TPG and thus mean PAP reflect the steady component of potential energy, i.e. the heat dissipated in the microcirculation [10]. Mean PAP and PVRI are useful measurements reflecting the opposition to the mean component of flow and the functional status of the distal (resistive) pulmonary vasculature. However, they do not take into account the pulsatile component of hydraulic load, which is mainly related to the proximal (elastic) PAs. The precise measurements of instantaneous pulsatile pressure and wave reflections require the use of expensive, high-fidelity pressure catheters instead of the commonly used fluid-filled catheters.

In the normal pulmonary vasculature, proximal PAs are highly distendable. The normal pulmonary circulation exhibits very little wave reflection, and the composite reflected pressure wave arrives during the early diastolic period [10]. Earlier, increased wave reflection may impede the ongoing RV ejection and thus impair right ventricular-arterial coupling in both primary $\mathrm{PH}$ and chronic pulmonary thromboembolism. In patients with primary $\mathrm{PH}$, the extent of wave reflection is large at rest and the composite reflected pressure wave arrives during the mid-portion of RV ejection [43]. Patients with chronic pulmonary thromboembolism have increased anticipated wave reflection compared with patients with primary $\mathrm{PH}$, probably because the functional reflection site is more proximal in the former patient group [91, 92]. In PH, increased PVR, decreased PA compliance and complex changes in the pulse wave reflection site lead to increased pulsatile load, as attested to by increased PA pulse pressure (PP; equal to systolic minus diastolic PAP) and increased wave reflection [43, 91]. Some authors have suggested that patients with chronic pulmonary thromboembolism have a higher PP than patients with primary $\mathrm{PH}$ [93]. Others have shown that no cut-off PP value could help distinguish these two populations when the mean PAP level was accounted for $[91,94]$. In hyperkinetic/high-flow states, increased pulsatile load may be explained by increased stroke volume.

\section{Echocardiography}

Systolic pulmonary artery pressure: tricuspid regurgitation peak jet velocity

Continuous-wave Doppler transthoracic echocardiography can be used in subjects with TR to determine the RV systolic pressure minus RAP gradient with the simplified Bernouilli equation:

$$
\mathrm{RV} \text { systolic pressure }-\mathrm{RAP}=4 \mathrm{VTR}^{2}
$$

where VTR is the TR peak jet velocity. Assuming that systolic PAP equates RV systolic pressure in the absence of pulmonic stenosis and outflow tract obstruction the following is obtained:

$$
\text { Systolic PAP }=4 \mathrm{VTR}^{2}+\mathrm{RAP}
$$

Patients must be in sinus rhythm to ensure stable VTR recordings. According to the WHO recommendations, mild $\mathrm{PH}$ is defined as a resting systolic PAP of $40-50 \mathrm{mmHg}$, which corresponds to a tricuspid regurgitant velocity of $3.0-3.5 \mathrm{~m} \cdot \mathrm{s}^{-1}$ [1], assuming a fixed $5 \mathrm{mmHg}$ RAP. In a recent large-scale, echocardiographic study of 3,790 healthy subjects $(2,432$ females) from 1-89 yrs of age, a $37.9 \mathrm{mmHg} 95 \%$ upper limit was documented for systolic PAP at rest, which corresponds to a VTR of $2.64 \mathrm{~m} \cdot \mathrm{s}^{-1}$ assuming a fixed $10 \mathrm{mmHg}$ RAP [95]. This study supports the use of age- and BMI-corrected values in establishing the normal pressure range, since a systolic $\mathrm{PAP}>40 \mathrm{mmHg}$ was found in $6 \%$ of healthy subjects $>50 \mathrm{yrs}$ of age and $5 \%$ of healthy subjects with BMI $>30 \mathrm{~kg} \cdot \mathrm{m}^{-2}$ [95]. Male sex and LV septal and posterior wall thickness are also predictive of systolic PAP [95]. The level of physical training is also important to consider. In 
resting healthy males $<23 \mathrm{yrs}$, the $95 \%$ upper limit of mean VTR is 1.93 and $2.41 \mathrm{~m} \cdot \mathrm{s}^{-1}$ in nonathletes $(\mathrm{n}=14)$ and athletes $(\mathrm{n}=26)$, respectively [96].

Tricuspid regurgitation is common in healthy subjects, and increases in prevalence and severity as PAP increases. It is widely accepted that continuous wave Doppler echocardiography is a valuable tool for diagnosing $\mathrm{PH}$, with interobserver variability of $<5 \%$. However, some investigators were unable to document VTR in $40-70 \%$ of patients with proven $\mathrm{PH}$, mainly in cases of moderately elevated PAP or because of poor acoustic windows [97]. Finally, as Doppler estimates of systolic PAP are operator-dependent, inter- and intra-observer reproducibility must be checked.

Doppler-derived systolic PAP values are strongly correlated with pressure measured with catheterisation in numerous studies [98, 99]. In other studies, Doppler values markedly underestimated systolic PAP $[45,96,100,101]$. Systolic PAP values measured by catheterisation and estimated by Doppler were poorly related during dynamic changes [45]. Catheterisation therefore remains the gold standard in establishing the diagnosis of $\mathrm{PH}$, while Doppler allows a serial, noninvasive follow-up of PA haemodynamics.

\section{Diastolic pulmonary artery pressure}

The simplified Bernouilli equation also allows determination of diastolic PAP in normal subjects and subjects with $\mathrm{PH}$ :

$$
\text { Diastolic PAP }=4 \text { VEDIP }^{2}+\text { RAP }
$$

where VEDIP is the end-diastolic velocity of the pulmonic insufficiency jet and RAP is a surrogate for the RV end-diastolic pressure [102]. Satisfactory pulmonary flow recordings are obtained in a majority of normal subjects and in $>90 \%$ of subjects with $\mathrm{PH}$.

\section{Mean pulmonary artery pressure}

Mean PAP can be approximated either by measuring the early-diastolic velocity of the pulmonic insufficiency jet (VeDip) or by measuring time intervals. The first method [102] is based on the following equation:

$$
\text { Mean PAP }=4 \mathrm{VeDIP}^{2}+\mathrm{RAP}
$$

The correlation with catheterisation is weak, although it may improve in cases where only patients with heart rates of $60-100$ beats $\cdot$ min $^{-1}$ are considered [103].

The second method relies on the observation that the pulmonary flow velocity signal is dome shaped in normal subjects while it is more triangular, with an earlier peak flow, in patients with $\mathrm{PH}$. In these patients, time-to-peak flow (i.e. acceleration time (AcT)) is decreased and KitAKABE et al. [104] have documented a high correlation $(\mathrm{r}=0.88)$ between AcT and $\log _{10}$ mean PAP. In some patients, premature deceleration of pulmonary systolic flow may result in mid-systolic notching, especially in severe $\mathrm{PH}$ or when there is an early return of the reflected wave (e.g. proximal obstruction) [105]. Consistently, patients with chronic pulmonary thromboembolism (i.e. proximal obstruction) have a shorter time-to-peak pressure than patients with primary $\mathrm{PH}$ (distal obstruction) $[91,92]$. Finally, AcT may also be prolonged in patients with decreased RV function and/or increased preload. Several studies have confirmed the predictive value of a decreased AcT for diagnosing $\mathrm{PH}$, with a $90-100 \mathrm{~ms}$ threshold $[106,107]$. The pre-ejection time / AcT ratio is also increased and correlates with PAP in patients with PH.

\section{Right atrial pressure}

The enlargement of the right atria reflects increased RAP. A precise estimation of RAP is especially needed in PH patients because increased RAP reflects $\mathrm{RV}$ dysfunction and is a strong predictor of outcome, and also because Doppler estimates of PAP depend upon the RAP value. This may be of critical importance for Doppler-derived diastolic PAP since RAP is a much higher percentage of diastolic than systolic PAP. In practice, the RAP may be arbitrarily fixed [102], clinically evaluated by the jugular venous pulse [2], or echocardiographically measured by the inferior vena cava collapse with spontaneous respiration [108]. KIRCHER et al. [108] have suggested that per cent collapse $\geqslant 50 \%$ or $<50 \%$ reflect RAP values of $<10 \mathrm{mmHg}$ or $\geqslant 10 \mathrm{mmHg}$, respectively. Given that RAP increases with PAP, a fixed RAP value tends to overestimate or underestimate low and high PAP values, respectively [109]. Recently, a new index of RV filling pressure has been described, namely the tricuspid $\mathrm{E} / \mathrm{Ea}$ ratio, where $\mathrm{E}$ is Doppler tricuspid inflow velocity and $\mathrm{Ea}$ is the tissue-Doppler early diastolic velocity of the tricuspid annulus [110]. Mean RAP was linearly related to $\mathrm{E} / \mathrm{Ea}$, and $\mathrm{E} / \mathrm{Ea}$ ratio $>6$ has a sensitivity of $79 \%$ and a specificity of $73 \%$ for mean RAP $\geqslant 10 \mathrm{mmHg}$ [110]. Finally, Doppler-derived hepatic vein systolic filling and filling fraction are negatively related to mean RAP, but the specificity and sensitivity of these indices over a large RAP range are still under study.

\section{Right ventricular function}

Given the complex architecture of the RV, indices quantifying RV diameter, area or volume are not always reproducible and are highly operator- and model-dependent. Following pressure overload, RV enlargement is best evidenced on the apical fourchamber view, and is often associated with a rounded rather than triangular (physiological) shape. The RV fractional area change in the apical four-chamber view is decreased. An RV/LV area ratio ranging from 0.6-1 indicates mild $\mathrm{RV}$ dilation, while severe $\mathrm{RV}$ dilation is associated with a ratio $>1$ [111]. The RV function may be indirectly estimated by using the global RV function index and the velocity of the tricuspid annulus plane. The Doppler global RV function index is defined as the sum of RV isovolumic contraction and relaxation times divided by ejection time [112]. The index is calculated by dividing the TR jet duration minus 
pulmonary jet duration difference by pulmonary jet duration. The global RV function index is a useful, independent predictor of adverse outcome in patients with $\mathrm{PH}$, and patients with an index $<0.83$ have a more favourable survivorship [113]. Doppler tissue imaging can be used to calculate the velocity of the tricuspid annulus plane which is positively correlated with RV systolic function [114].

\section{Interventricular septum and left ventricle function}

$\mathrm{PH}$ results in RV systolic overload characterised by leftward septal shift at end-systole and early diastole, the septum behaving has an intrinsic part of the RV [32, 111]. RV geometric changes influence LV function, and prolonged LV isometric relaxation, reduction in LV early diastolic filling and paradoxic septal motion in systole are also observed [32, 111]. Deceleration time of early transmitral flow is decreased and negatively correlates with LV deformity index and PVR [115]. Interventricular septum kinetics are best evidenced on the parasternal short-axis view. Significant tricuspid insufficiency leads to RV diastolic overload with the RV filling at the expense of the LV, together with leftward septal shift at end-diastole, unchanged $\mathrm{LV}$ isometric relaxation and a reduction in the contribution of left atrial systole to LV diastolic filling [32]. In PH, the underfilling of the LV may be due to reduced pulmonary venous return, left-to-right interatrial shunting and/or interventricular septal shift due to RV overload. In patients with chronic thromboembolic $\mathrm{PH}$, the impairment of $\mathrm{LV}$ filling is potentially reversible, as attested to by the increases in the transmitral early to atrial filling velocity ratio (E/A) quickly after pulmonary thromboendarteriectomy, with postoperative E/A $>1.5$ correlating with the absence of severe, residual PH [116].

\section{Right ventricle hypertrophy and other findings}

$\mathrm{RV}$ free wall thickness is measured at end-diastole using the subcostal view, and normal values are $\leqslant 4 \mathrm{~mm}$. Marked ( $>10 \mathrm{~mm})$, heterogeneous RV hypertrophy is currently found in chronic cor pulmonale, while mild RV hypertrophy $(6-8 \mathrm{~mm})$ or subnormal values are found in acute cor pulmonale [111]. Echocardiography may reveal effusive pericarditis. Transoesophageal echocardiography and contrast echocardiography may be especially valuable for diagnosing a patent foramen ovale. Colour Doppler indices relying on the jet length into the RA allow the severity of TR to be quantified. Measurements of PA diameter (normal value $<2.35 \mathrm{~cm}$ ) belong to the systematic echocardiographic analysis of $\mathrm{PH}$ patients. Finally, echocardiography may diagnose an underlying cardiac disease responsible for secondary $\mathrm{PH}$.

In primary $\mathrm{PH}$, higher mean PAP are associated with more pronounced abnormalities in the septal curvature and depressed RV contractile function [45]. Patients with poor performance on the 6-min walk test exhibited a greater degree of RV dilation, more pronounced septal displacement in diastole, larger pericardial effusions, and more severe TR [45]. Patients with Class IV symptoms are more likely to have pericardial effusions.

\section{Other techniques}

\section{Imaging}

Pulmonary magnetic resonance angiography (PMRA) is a promising imaging tool for the identification of patients with $\mathrm{PH}$. In a recent study, gadoliniumenhanced PMRA showed that a right PA diameter $>28 \mathrm{~mm}$, along with the measurement of diameter of the proximal-to-distal tapering of the PAs and absence of intravascular filling defects, allow the diagnosis of $\mathrm{PH}$ with a high sensitivity and high negative predictive value [117]. These results confirm earlier studies with computed tomography scanning [118] and magnetic resonance (MR) angiograms [119, 120]. The diameter of the descending right PA on chest radiography has been used for a long time to screen for the prevalence of PH in populations [121], and others indices are currently used, namely the hilar width percent and hilar/thoracic index percent.

Classic pulmonary angiography and ventilation/ perfusion scans help diagnose chronic pulmonary thromboemboli. In primary $\mathrm{PH}$, quantitative analysis of the irregularities of lung perfusion scans could be related to the severity of the disease [122]. Some authors have used thallium scintigraphy and cine MR imaging to study RV pressure overload in $\mathrm{PH}$ patients. Perfusion abnormalities suggestive of RV ischaemia are associated with RV dysfunction [123]. Finally, first-pass radionuclide angiography and gated stress myocardial perfusion imaging [124] allow the routine evaluation of RVEF, bearing in mind that $\mathrm{RVEF}$ reflects afterload rather than RV contractility.

\section{Electrocardiogram criteria}

Although the echocardiogram has decreased dependency on the electrocardiogram (ECG) and catheterisation to diagnose $\mathrm{PH}$ and monitor $\mathrm{RV}$ function, certain ECG parameters nevertheless remain important in patient management. Those reflecting right atrial and ventricular overload have been associated with decreased survival [125]. The p-wave amplitude in lead II, a $p \geqslant 0.25 \mathrm{mV}$ in lead II, the presence of a qR pattern in $\mathrm{V} 1$, and WHO criteria for $\mathrm{RV}$ hypertrophy are highly predictive of an adverse outcome [125].

\section{Natriuretic peptides}

In patients with $\mathrm{PH}$, a high level of plasma atrial natriuretic peptide (ANP) and brain natriuretic peptide (BNP) negatively correlates with parameters of RV function [126-128]. Following prostacyclin treatment, the decreases in both ANP and BNP parallel pulmonary vasodilatation and haemodynamic improvement [127, 128]. During follow-up, a further increase 
in plasma BNP is an independent predictor of mortality. Repeated plasma BNP measurement may well offer a noninvasive tool for identifying patients refractory to treatments [127], although it remains to be established how the predictive value of BNP compares to that of other indices, e.g. the walking distance.

\section{Predictors of adverse outcomes in patients with pulmonary hypertension}

The prognosis is related essentially to the underlying illness, the severity of the $\mathrm{PH}$ and the $\mathrm{RV}$ function. Some diseases leading to secondary $\mathrm{PH}$ (table 1) carry a high specific risk, e.g. underlying liver function is a major prognosis factor in patients with POPH. Predictors of prognosis cannot be detailed for all forms of $\mathrm{PH}$, and only $\mathrm{PH}$ in the setting of primary disease, COPD and heart failure will be detailed below.

\section{Primary pulmonary hypertension}

Several studies have focused on the haemodynamic predictors of adverse outcomes in primary $\mathrm{PH}$. Although the heterogeneity of the clinical course of primary $\mathrm{PH}$ has been acknowledged, the prognosis appears mainly related to both RV function (static parameters) and to the amount of pulmonary vasodilatation in reserve (dynamic parameter). Adverse prognosis correlates with the NYHA functional classification $[40,61]$, the distance walked during the 6-min walk test [18, 39], the mean RAP [40, 60, 65, 129, 130], cardiac or stroke volume index $[40,60,61,129-131]$ and systemic arterial and mixed $S_{\mathrm{v}, \mathrm{O}_{2}}[60,61,64]$. Prognosis also relates to mean PAP and PVRI (or PVR) in most studies, although conflicting results have been reported in some studies. The lack of pulmonary vasodilatory reserve is also associated with poor prognosis [60, 71, 80-82, 132]. Echocardiographic predictors of adverse outcomes in primary PH include pericardial effusion, right atrial enlargement, septal displacement and an increased Doppler global RV function index [113, 133, 134]. Numerous other prognostic factors have been described, including the forced vital capacity [60], pulmonary $\mathrm{Sa}_{\mathrm{a}} \mathrm{O}_{2}$ [132], oxygen saturation at peak distance during the 6-min walk test [18], anticoagulant therapy [132] and increased serum uric acid $[64,65]$. Overall, determining the walking distance, stroke volume index, mean RAP, pulmonary vasodilatory reserve, serum uric acid and echocardiographic characteristics should help in predicting primary $\mathrm{PH}$ clinical course.

The results of two recent studies deserve particular attention. Sitbon et al. [135] have tested the predictive value of the responses to a 3-month continuous infusion of epoprostenol in primary $\mathrm{PH}$ patients in NYHA functional class III-IV. In the Cox model of multivariate analysis including both baseline and 3month clinical and haemodynamic variables, the persistence of NYHA functional class III-IV and the absence of fall in PVRI $>30 \%$ relative to baseline at 3 months, and a history of right heart failure, were associated with a poor 5-yr survival. This suggests that haemodynamic responses to 3-month prostaglandin $\mathrm{I}_{2}$ infusion may help diagnose a subset of primary $\mathrm{PH}$ in whom lung transplantation could be proposed [135]. Furthermore, WensEl et al. [65] have performed symptom-limited exercise testing, pulmonary function test, cardiac catheterisation and uric acid measurements in primary $\mathrm{PH}$. They reported that low peak $V^{\prime} \mathrm{O}_{2}$ and low peak exercise systolic arterial pressure were the strongest predictors of impaired survival. The predictive value of the $V^{\prime} \mathrm{E} / V^{\prime} \mathrm{CO}_{2}$ slope was not tested due to the high percentage of patients with a patent foramen ovale [65]. Patients with two risk factors, namely peak $V^{\prime} \mathrm{O}_{2} \leqslant 10.4 \mathrm{~mL} \cdot \mathrm{kg}^{-1} \cdot \mathrm{min}^{-1}$ and peak exercise systolic arterial pressure $\leqslant 120 \mathrm{mmHg}$ had poor survival rates at 12 months $(23 \%)$, whereas patients with one or none of these risk factors had $79 \%$ and $97 \%$ survival rates, respectively [65]. The prognostic consequence of a low systemic pressure could be explained by greater sensitivity and more severe dysfunction of the RV as a result of ischaemia [123]. Finally, amongst the new therapeutic approaches for primary $\mathrm{PH}$, several trials, either published or in progress, have suggested benefits for a patient assigned to a specific treatment group, and further studies are needed to confirm and summarise new therapeutic guidelines.

\section{Chronic obstructive pulmonary disease}

In COPD patients, factors related to survival include forced expiratory volume in one minute, $P \mathrm{a}, \mathrm{O}_{2}$ and mean PAP [24]. In patients receiving long-term oxygen therapy, mean PAP is the best prognostic factor [136]. Finally, the higher the mean PAP, the higher the risk of hospitalisation for acute exacerbation [137].

\section{Heart failure}

As far as right heart failure is concerned, there is a complex interplay between the severity and the cause of PH. Despite a tendency towards higher PAP, patients with Eisenmenger syndrome have lower mean RAP and greater systemic cardiac output than those with primary $\mathrm{PH}$ [138], and the preservation of biventricular function could explain the more favourable outcome in the former group [138, 139]. The degree of hypoxaemia at baseline is a strong predictor of survival in the Eisenmenger syndrome.

The RVEF is an independent prognostic factor in patients with $\mathrm{PH}$ complicating chronic heart failure [140]. In patients with advanced heart failure, RVEF $\geqslant 0.35$ at rest and during exercise is a more powerful predictor of survival than $V^{\prime} \mathrm{O}_{2}$ [46]. A few recent studies have suggested that hyperventilatory response to exercise, as measured by increased $V^{\prime} \mathrm{E} / V^{\prime} \mathrm{CO}_{2}$ slope, may be a prognostic factor of poor survival, but this point remains to be confirmed in large population studies. Mean PAP is particularly important in stratifying risk in cardiomyopathy caused by myocarditis [141]. Patients with $\mathrm{PH}$ are a particularly high-risk 
group, probably because PH may develop more acutely, overwhelming compensatory mechanisms such as RV hypertrophy.

In $\mathrm{PH}$ patients evaluated for cardiac transplantation, patients with reversible (or reactive) haemodynamics following provocative vasodilatory therapy have better prognosis than patients with irreversible (or fixed) $\mathrm{PH}[37]$.

\section{Conclusion}

The rational management of patients with pulmonary hypertension relies on the careful assessment of their haemodynamic profile. Cardiac catheterisation allows for the precise establishment of the diagnosis and the type of pulmonary hypertension, the severity of the disease, the consequences on right heart function, and the amount of vasodilatation in reserve. The precise evaluations of exercise capacity (6-min walk test), right atrial pressure, stroke index and vasodilator challenge responses are of major importance, given their prognostic values. Echocardiography is especially valuable in the serial assessment of pulmonary artery pressures and right and left heart function. The underlying cause of pulmonary hypertension must be recognised and any treatable factor potentially involved in pulmonary vasoconstriction and right ventricle failure must be prevented or treated. New developments in vascular biology have improved understanding of the underlying causes of vascular obstruction, remodelling and vasoconstriction in pulmonary hypertension. Recent therapeutic strategies in primary pulmonary hypertension have reported the significant benefits of oral prostacyclin analogues and oral endothelin-receptor antagonists. The outlook in the field of genetic testing is promising. Overall, the careful haemodynamic evaluation of pulmonary hypertension patients may optimise new diagnosis and therapeutic strategies.

\footnotetext{
Acknowledgements. The authors thank R. Naeije, F-X. Blanc and S. Carrodus for their helpful comments. The authors apologise to many investigators whose work that could not be cited because of space limitation.
}

\section{References}

1. Rich S. Executive summary from the world symposium on primary pulmonary hypertension 1998. Evian, France, September 6-10, 1998, co-sponsored by the World Health Organization. www.who.int/ncd/ cvd/pph.html. Date updated: June 2002.

2. Weir EK, Michelakis ED, Archer SL, Rubin LJ. Pulmonary hypertension. In: Willerson JT, Cohn JN, eds. Cardiovascular Medicine. 2nd edn. Philadelphia, Churchill Livingstone, 2000; pp. 1856-1884.

3. Smiley I, Rich S, McLaughlin VV, eds. Clinics in Chest Medicine. Philadelphia, WB Saunders Company, 2001; pp. 385-595.

4. Reeves JT, Groves BM. Approach to patient with pulmonary hypertension. In: Weir EK, Reeves JT, eds.
Pulmonary hypertension. Mount Kisco, NY, Futura, 1984; pp. 1-44.

5. Moraes D, Loscalzo J. Pulmonary hypertension: newer concepts in diagnosis and management. Clin Cardiol 1997; 20: 676-682.

6. Rich S, Braunwald E, Grossman W. Pulmonary hypertension. In: Braunwald E, ed. Heart disease. A Textbook of Cardiovascular Medicine. 5th edn. Philadelphia, WB Saunders Company, 1997; pp. 780-806.

7. Rich S, Dantzker DR, Ayres S, et al. Primary pulmonary hypertension: a national prospective study. Ann Intern Med 1987; 107: 216-223.

8. Rubin LJ. Primary pulmonary hypertension. $N$ Engl J Med 1997; 336: 111-117.

9. Humbert M, Trembath RC. Genetics of pulmonary hypertension: from bench to bedside. Eur Respir $J$ 2002; 20: 741-749.

10. Milnor WR. Hemodynamics. Baltimore, William \& Wilkins. 1982; pp. 1-390.

11. Fishman AP. Handbook of Physiology. Bethesda, MD, American Physiological Society, 1985; pp. 92166.

12. Wood P. Diseases of the heart and circulation. London, Eyre and Spottiswoode, 1962.

13. McGregor M, Sniderman A. On pulmonary vascular resistance: the need for more precise definition. Am J Cardiol 1985; 55: 217-221.

14. Keller CA, Shepard JW, Chun DS, Vasquez P, Dolan GF. Pulmonary hypertension in chronic pulmonary disease. Multivariate analysis. Chest 1986; 920: 185-192.

15. Scharf SM, Iqbal M, Keller C, Criner G, Lee S, Fessler HE, for the National Emphysema Treatment Trial (NETT) research group. Hemodynamic characterization of patients with severe emphysema. Am J Respir Crit Care Med 2002; 166: 314-322.

16. Kessler R, Faller M, Weitzenblum E, et al. "Natural history" of pulmonary hypertension in a series of 131 patients with chronic obstructive lung disease. Am J Respir Crit Care Med 2001; 164: 219-224.

17. Dantzker DR, d'Alonzo GE, Bower JS, Popat K, Crevey BJ. Pulmonary gas exchange during exercise in patients with chronic obliterative pulmonary hypertension. Am Rev Respir Dis 1984; 130: 412-416.

18. Paciocco G, Martinez FJ, Bossone E, Pielsticker E, Gillespie B, Rubenfire M. Oxygen desaturation on the six-minute walk test and mortality in untreated primary pulmonary hypertension. Eur Respir J 2001; 17: 647-652.

19. Channick RN, Simonneau G, Sitbon O, et al. Effects of the dual endothelin-receptor antagonist bosentan in patients with pulmonary hypertension: a randomised placebo-controlled study. Lancet 2001; 358: 11191123.

20. Rubin LJ, Badesh DB, Barst RJ, et al. Bosentan therapy for pulmonary arterial hypertension. $N$ Engl $J$ Med 2002; 346: 896-903.

21. Hervé P, Humbert M, Sitbon O et al. Pathobiology of pulmonary hypertension: the role of platelets and thrombosis. In: Smiley I, Rich S, McLaughlin VV, eds. Clinics in Chest Medicine: Pulmonary Hypertension. Philadelphia, WB Saunders Company, 2001; pp. 451458.

22. Nootens M, Kaufmann E, Rector T, et al. Neurohormonal activation in patients with right ventricular failure from pulmonary hypertension: relation to 
haemodynamic variables and endothelin levels. $J \mathrm{Am}$ Coll Cardiol 1995; 26: 1581-1585.

23. Smiley I, Rich S, McLaughlin VV, eds. Cardiology Clinics: The Right Ventricle. Philadelphia, WB Saunders Company, 1992; 10: pp. 1-196.

24. Schulman DS, Matthay RA. The right ventricle in pulmonary disease. In: Smiley I, Rich S, McLaughlin VV, eds. Cardiology Clinics: The Right Ventricle. Philadelphia, WB Saunders Company, 1992; pp. 111-135.

25. Horan L, Flowers N, Havelda C. Relation between right ventricular mass and cavity size: an analysis of 1500 human hearts. Circulation 1981; 64: 135-138.

26. Wiedemann HP, Matthay RA. Cor pulmonale. In: Braunwald E, ed. Heart Disease. A Textbook of Cardiovascular Medicine. 5th edn. Philadelphia. WB Saunders company, 1997; pp. 1604-1625.

27. MacNee W. Pathophysiology of cor pulmonale in chronic obstructive pulmonary disease (Part one). Am J Respir Crit Care Med 1994; 150: 833-852.

28. Brent BN, Berger HJ, Matthay RA, Mahler D, Pytlik L, Zaret BL. Physiologic correlates of right ventricular ejection fraction in chronic obstructive pulmonary disease: a combined radionuclide and hemodynamic study. Am J Cardiol 1982; 5: 255-262.

29. Maddahi J, Berman D, Matsuoka D, Waxman A, Forrester J, Swan H. Right ventricular ejection fraction during exercise in normal subjects and in coronary artery disease patients: assessment by multiple-gated equilibrium scintigraphy. Circulation 1980; 62: 133-140.

30. Morrison D, Sorensen S, Caldwell J, et al. The normal right ventricular response to supine exercise. Chest 1982; 82: 686-691.

31. Weitzenblum E, Chaouat A. Right ventricular function in COPD. Can it be assessed reliably by the measurement of right ventricular ejection fraction? Chest 1998; 113: 587-589.

32. Louie EK, Rich S, Levitsky S, Brundage BH. Doppler echocardiographic demonstration of the differential effects of right ventricular pressure and volume overload on left ventricular geometry and filling. J Am Coll Cardiol 1992; 19: 84-90.

33. Nootens M, Wolfkiel CJ, Chomka EV, Rich S. Understanding right and left ventricular systolic function and interactions at rest and with exercise in primary pulmonary hypertension. Am J Cardiol 1995; 75: 374-377.

34. Dhainaut JFA, Doise JM, Brunet F. Heart-lung interaction in chronic obstructive pulmonary disease. In: Derenne JP, Whitelaw WA, Similowski T, eds. Acute Respiratory Failure in Chronic Obstructive Pulmonary Disease. New York, Marcel Dekker Inc., 1996; pp. 267-302.

35. Fishman A. Chronic cor pulmonale. Am Rev Respir Dis 1976; 114: 775-794.

36. Richens JM, Howard P. Oedema in cor pulmonale. Clin Sci 1982; 62: 255-259.

37. Stobierska B, Awad H, Michler RE. The evolving management of acute right-sided heart failure in cardiac transplant recipients. $J$ Am Coll Cardiol 2001; 38: 923-931.

38. Janicki JS, Weber KT, Likoff MJ, Fishman AP. The pressure-flow response of the pulmonary circulation in patients with heart failure and pulmonary vascular disease. Circulation 1985; 72: 1270-1278.

39. Miyamoto S, Nagaya $\mathrm{N}$, Satoh $\mathrm{T}$, et al. Clinical correlates and prognostic significance of six-minute walk test in patients with primary pulmonary hypertension. Comparison with cardiopulmonary exercise testing. Am J Respir Crit Care Med 2000; 161: 487492.

40. d'Alonzo GE, Barst RJ, Ayres SM, et al. Survival in patients with primary pulmonary hypertension. Results from a national prospective registry. Ann Intern Med 1991; 115: 343-349.

41. Rhodes J, Barst RJ, Garofano RP, Thoele DG, Gersony WM. Hemodynamic correlates of exercise function in patients with primary pulmonary hypertension. J Am Coll Cardiol 1991; 18: 1738-1744.

42. Sun XG, Hansen JE, Oudiz RJ, Wasserman K. Exercise pathophysiology in patients with primary pulmonary hypertension. Circulation 2001; 104: 429_ 435 .

43. Laskey WK, Ferrari VA, Palevsky HI, Kussmaul WG. Pulmonary artery hemodynamics in primary pulmonary hypertension. J Am Coll Cardiol 1993; 21: 406412.

44. ATS statement: guidelines for the six-minute walk test. Am J Respir Crit Care Med 2002; 166: 111-117.

45. Hinderliter AL, Willis PW, Barst RJ, et al. Effects of long-term infusion of prostacyclin (epoprostenol) on echocardiographic measures of right ventricular structure and function in primary pulmonary hypertension. Circulation 1997; 95: 1479-1486.

46. di Salvo TG, Mathier M, Semigran MJ, Dec GW. Preserved right ventricular ejection fraction predicts exercise capacity and survival in advanced heart failure. J Am Coll Cardiol 1995; 25: 1143-1153.

47. Davidson CJ, Fishman RF, Bonow RO. Cardiac catheterization. In: Braunwald E, ed. Heart Disease. A Textbook of Cardiovascular Medicine. 5th edn. Philadelphia, WB Saunders Company, 1997; pp. 177-203.

48. Kern MJ. Hemodynamic data. In: Kern MJ, ed. The Cardiac Catheterization Handbook. 3rd edn. St Louis, Mosby, 1999; pp. 123-223.

49. Tartulier M, Bourret M, Deyrieux F. Pulmonary arterial pressures in normal subjects. Effects of age and muscular exercise. Bull Physiopathol Respir 1972; 8: 1295-1321.

50. Ehrsam RE, Perruchoud A, Oberholzer M, Bukart F, Herzog H. Influence of age on pulmonary haemodynamics at rest and during supine exercise. Clin Sci 1983; 65: 653-660.

51. Fowler NO. The normal pulmonary arterial pressureflow relationships during exercise. Am J Med 1969; 47: $1-2$.

52. Moraes DL, Colucci WS, Givertz MM. Secondary pulmonary hypertension in chronic heart failure. The role of the endothelium in pathophysiology and management. Circulation 2000; 102: 1718-1723.

53. Kafi SA, Mélot C, Vachiéry JL, Brimioulle S, Naeije R. Partitioning of pulmonary vascular resistance in primary pulmonary hypertension. $\mathrm{J}$ Am Coll Cardiol 1998; 31: 1372-1376.

54. Zidulka A, Hakim TS. Wedge pressure in large vs small pulmonary arteries to detect pulmonary venoconstriction. J Appl Physiol 1985; 59: 1329-1332.

55. Krokwa MJ. Hepatopulmonary syndrome versus portopulmonary hypertension: distinctions and dilemnas. Hepatology 1997; 25: 1282-1284.

56. Kuo PC, Plotkin JS, Johnson LB, et al. Distinctive clinical features of portopulmonary hypertension. Chest 1997; 112: 980-986. 
57. Hervé P, Sztrymf B, Sitbon O. Pulmonary hypertension associated with portal hypertension. In: Peacock AJ, Rubin L, eds. Pulmonary Circulation. 2nd edn. London, Edward Arnold publishers, 2002 (in press).

58. Hoeper MM, Maier R, Tongers J, et al. Determination of cardiac output by Fick method, thermodilution, and acetylene rebreathing in pulmonary hypertension. Am J Respir Crit Care Med 1999; 160: 535-541.

59. Nootens MT, Berarducci LA, Kaufmann E, Devries S, Rich S. The prevalence and significance of a patent foramen ovale in pulmonary hypertension. Chest 1993; 104: 1673-1675.

60. Sandoval J, Bauerle O, Palomar A, et al. Survival in primary pulmonary hypertension. Validation of a prognostic equation. Circulation 1994; 89: 1733-1744.

61. Higgenbottam T, Butt AY, Westerbeck R, Sharples L. Long term intravenous prostaglandin (epoprostenol or iloprost) for treatment of severe pulmonary hypertension. Heart 1998; 80: 151-155.

62. Sitbon O, Brenot F, Denjean A, et al. Inhaled nitric oxide as a screening vasodilator agent in primary pulmonary hypertension. A dose-response study and comparison with prostacyclin. Am J Respir Crit Care Med 1995; 151: 384-389.

63. McLaughlin VV, Genthner DE, Panella MM, Rich S. Reduction in pulmonary vascular resistance with longterm epoprostenol (prostacyclin) therapy in primary pulmonary hypertension. N Engl J Med 1998; 338: 273-277.

64. Nagaya N, Uematsu M, Satoh T, et al. Serum uric acid levels correlate with the severity and the mortality of primary pulmonary hypertension. Am J Respir Crit Care Med 1999; 160: 487-492.

65. Wensel R, Optiz CF, Anker SD, et al. Assessment of survival in patients with primary pulmonary hypertension. Importance of cardiopulmonary testing. Circulation 2002; 106: 319-324.

66. Stein P, Sabbah H, Anbe D, Marzilli M. Performance of the failing and nonfailing right ventricle of patients with pulmonary hypertension. Am J Cardiol 1979; 44: 1050-1055.

67. Fedullo PF, Auger WR, Kerr KM, Rubin LJ. Chronic thromboembolic pulmonary hypertension. $N$ Engl $J$ Med 2001; 345: 1465-1472.

68. Archer S, Rich S. Primary pulmonary hypertension. A vascular biology and translational research "work in progress". Circulation 2000; 100: 2781-2791.

69. Rapp AH, Lange RA, Cigarroa JE, Keeley EC, Hillis LD. Relation of pulmonary arterial diastolic and mean pulmonary arterial wedge pressure in patients with and without pulmonary hypertension. Am J Cardiol 2001; 88: 823-824.

70. Mandel J, Mark EJ, Hales CA. Pulmonary venoocclusive disease. Am J Respir Crit Care Med 2000; 162: 1964-1973.

71. Naeije R, Vachiéry JL. Medical therapy of pulmonary hypertension. Conventional therapies. In: Smiley I, Rich S, McLaughlin VV, eds. Pulmonary hypertension. Clinics in Chest Medicine. Philadelphia, WB Saunders Company, 2001; pp. 517-527.

72. Pepke-Zaba J, Higenbottam TW, Dinh-Xuan AT, Stone D, Wallwor J. Inhaled nitric oxide as a cause of selective pulmonary vasodilatation in pulmonary hypertension. Lancet 1991; 338: 1173-1174.

73. Weir EK, Rubin LJ, Ayres SM, et al. The acute administration of vasodilators in primary pulmonary hypertension. Experience from the National Institutes of Health registry on primary pulmonary hypertension. Am Rev Respir Dis 1989; 140: 1623-1630.

74. Barst RJ, Rubin LJ, Long WA, et al. A comparison of continuous epoprostenol (prostacyclin) with conventional therapy for primary pulmonary hypertension. $N$ Engl J Med 1996; 334: 296-301.

75. Sitbon O, Humbert M, Jagot JL, et al. Inhaled nitric oxide as a screening agent for sagely identifying responders to oral calcium-channel blockers in primary pulmonary hypertension. Eur Respir J 1998; 12: 265-270.

76. Krasuski RA, Warner JJ, Wang A, Harrison JK, Tapson VF, Bashore TM. Inhaled nitric oxide selectively dilates pulmonary vasculature in adult patients with pulmonary hypertension, irrespective of etiology. J Am Coll Cardiol 2000; 36: 2204-2211.

77. Reeves JT, Groves BM, Turkevich D. The case for treatment of selected patients with primary pulmonary hypertension. Am Rev Respir Dis 1986; 134: 342-346.

78. Palevsky HI, Long W, Crow J, Fishman AP. Prostacyclin and acetylcholine as screening agents for acute pulmonary vasodilator responsiveness in primary pulmonary hypertension. Circulation 1990; 82: 2018-2026.

79. Robbins IM, Barst RJ, Rubin LJ. Pulmonary vasoreactivity in PPH. J Am Coll Cardiol 2001; 28: 1267-1268.

80. Rich S, Brundage B, Levy P. The effect of vasodilator therapy on the clinical outcome of patients with primary pulmonary hypertension. Circulation 1985; 71: 1191-1196.

81. Raffy O, Azarian $\mathrm{R}$, Brenot $\mathrm{F}$, et al. Clinical significance of the pulmonary vasodilator response during short-term infusion of prostacyclin in primary pulmonary hypertension. Circulation 1996; 93: 484 488.

82. Rich S, Kaufmann E, Levy PS. The effects of high doses of calcium-channel blockers on survival in primary pulmonary hypertension. $N$ Engl $J$ Med 1992; 327: 76-81.

83. Ricciardi MJ, Knight BP, Martinez FJ, Rubenfire M. Inhaled nitric oxide in primary pulmonary hypertension. A safe and effective agent for predicting response to nifedipine. J Am Coll Cardiol 1998; 32: 1068-1073.

84. Cope DK, Allison RC, Parmentier JL, Miller JN, Taylor AE. Measurement of effective pulmonary capillary wedge pressure using the pressure profile after pulmonary artery occlusion. Crit Care Med 1986; 14: $16-22$.

85. Grimbert FA. Effective pulmonary capillary pressure. Eur Respir J 1988; 1: 297-301.

86. Naeije R, Lipski A, Abramowicz M, et al. Nature of pulmonary hypertension in congestive heart failure. Effects of cardiac transplantation. Am J Respir Crit Care Med 1994; 149: 881-887.

87. Castelain V, Chemla D, Humbert M, et al. Pulmonary artery pressure-flow relations after prostacyclin in primary pulmonary hypertension. Am J Respir Crit Care Med 2002; 165: 338-340.

88. Fesler P, Pagnamenta A, Vachiéry JL, et al. Elevated pulmonary capillary pressure in pulmonary arterial hypertension. Eur Respir J 2002 (in press).

89. Pagnamenta A, Fesler P, Vandinivit A, Brimioulle S, Naeije R. The pulmonary vascular effects of dobutamine 
in experimental pulmonary hypertension. Crit Care Med 2002 (in press)

90. Brimioulle $\mathrm{S}$, de Cannière $\mathrm{D}$, Vachiéry JL, Antoine M, Naeije R, Le Clerc JL. Pulmonary vascular impedance predicting right ventricular failure after heart transplantation. Intensive Care Med 1997; 23: S78.

91. Castelain V, Hervé P, Lecarpentier Y, Duroux P, Simonneau G, Chemla D. Pulmonary artery pulse pressure and wave reflection in chronic pulmonary thromboembolism and primary pulmonary hypertension. J Am Coll Cardiol 2001; 37: 1085-1092.

92. Chemla D, Castelain V, Simonneau G, Lecarpentier Y, Hervé P. Pulse wave reflection in pulmonary hypertension. J Am Coll Cardiol 2002; 39: 743.

93. Nakayama Y, Nakanishi N, Sugimachi $\mathrm{M}$, et al. Characteristics of pulmonary artery pressure waveform for differential diagnosis of chronic pulmonary thromboembolism and primary pulmonary hypertension. J Am Coll Cardiol 1997; 29: 1311-1316.

94. Sadeghi HM, Keramati S, Sawhney N, et al. Chronic thromboembolic pulmonary hypertension and primary pulmonary hypertension: a comparison of invasive hemodynamic data. Circulation 2000; 102: Suppl. II, 716.

95. McQuillan BM, Picard MH, Leavitt M, Weyman AE. Clinical correlates and reference intervals for pulmonary artery systolic pressure among echocardiographically normal subjects. Circulation 2001; 104: 2797 2802.

96. Bossone E, Rubenfire M, Bach DS, Ricciardi M, Armstrong WF. Range of tricuspid regurgitation velocity at rest and during exercise in normal adult men: implications for the diagnosis of pulmonary hypertension. J Am Coll Cardiol 1999; 33: 1662-1666.

97. Homma A, Anzueto A, Peters JI, et al. Pulmonary artery systolic pressures estimated by echocardiogram vs cardiac catheterization in patients awaiting lung transplantation. J Heart Lung Transplant 2001; 20: 833-839.

98. Berger M, Haimowitz A, van Tosh A, Berdoff RL, Goldberg E. Quantitative assessment of pulmonary hypertension in patients with tricuspid regurgitation using continuous wave Doppler ultrasound. J Am Coll Cardiol 1985; 6: 359-365.

99. Chow LC, Dittrich HC, Hoit BD, Moser KM, Nicol PH. Doppler assessment of changes in right-sided cardiac hemodynamics after pulmonary thromboendarteriectomy. Am J Cardiol 1988; 61: 1092-1097.

100. Tramarin R, Torbicki B, Marchandise B, Laaban JP, Morpugi M. Doppler echocardiographic evaluation of pulmonary artery pressure in chronic pulmonary obstructive disease. A European multicentre study. Working group on non-invasive evaluation of pulmonary artery pressure. European office of the WHO, Copenhagen. Eur Heart J 1991; 12: 103-111.

101. Brecker SJ, Gibbs JS, Fox KM, Yacoub MH, Gibson DG. Comparison of Doppler derived haemodynamic variables and simultaneous high fidelity pressure measurements in severe pulmonary hypertension. Br Heart J 1994; 72: 384-389.

102. Masuyama T, Kodama K, Kitakabe A, Sato H, Nanto $H$, Inoue $M$. Continuous-wave Doppler echocardiographic detection of pulmonary regurgitation and its application to noninvasive estimation of pulmonary artery pressure. Circulation 1986; 74: 484 492.

103. Chan KL, Currie PJ, Seward JB, Hagler DJ,
Mair DD, Tajik AJ. Comparison of three Doppler ultrasound methods in the prediction of pulmonary artery pressure. J Am Coll Cardiol 1987; 9: 549-554.

104. Kitakabe A, Inoue M, Asao M, et al. Noninvasive evaluation of pulmonary hypertension by a pulsed Doppler technique. Circulation 1983; 68: 302-309.

105. Naeije R, Torbicki A. More on the noninvasive diagnosis of pulmonary hypertension: Doppler echocardiography revisited. Eur Respir J 1995; 8: 14451449.

106. Dabestani A, Mahan G, Gardin JM, et al. Evaluation of pulmonary artery pressure and resistance by pulsed Doppler echocardiography. Am J Cardiol 1987; 59: 662-668.

107. Torbicki A, Skwarski K, Hawrylkiewicz I, Pasierski T, Miskiewicz Z, Zielinski J. Attempts at measuring pulmonary arterial pressure by means of Doppler echocardiography in patients with chronic lung disease. Eur Respir J 1989; 2: 856-860.

108. Kircher BJ, Himelman RB, Schiller NB. Noninvasive estimation of right atrial pressure from the inspiratory collapse of the inferior vena cava. Am J Cardiol 1990; 15: 493-496.

109. Lavine SJ. Noninvasive estimation of right-sided pressures from spectral Doppler recordings of tricuspid and pulmonic regurgitant velocities. Chest 1999; 116: 1-3.

110. Nageh MF, Kopelen HA, Zoghbi WA, Quinones MA, Nagueh SF. Estimation of mean right atrial pressure using tissue Doppler imaging. Am J Cardiol 1999; 84: 1448-1451.

111. Jardin F, Dubourg O, Bourdarias JP. Echocardiographic pattern of cor pulmonale. Chest 1997; 111: 209-217.

112. Tei C, Dujardin KS, Hodge DO, et al. Doppler echocardiographic index for assessment of global right ventricular function. J Am Soc Echocardiogr 1996; 9: 838-847.

113. Yeo TC, Dujardin KS, Tei C, Mahoney DW, McGoon MD, Seward JB. Value of a Doppler-derived index combining systolic and diastolic time in predicting outcome in primary pulmonary hypertension. Am J Cardiol 1998; 81: 1157-1161.

114. Moustapha A, Lim M, Saikia S, Kaushik V, Kang SH, Barasch E. Interrogation of the tricuspid annulus by Doppler tissue imaging in patients with chronic pulmonary hypertension: implications for the assessment of right-ventricular systolic and diastolic function. Cardiology 2001; 95: 101-104.

115. Nagaya N, Satoh T, Uematsu M, et al. Shortening of Doppler-derived deceleration time of early diastolic transmitral flow in the presence of pulmonary hypertension through ventricular interaction. $\mathrm{Am}$ J Cardiol 1997; 79: 1502-1506.

116. Mahmud E, Raisinghani A, Hassankhani A, et al. Correlation of left ventricular diastolic filling characteristics with right ventricular overload and pulmonary artery pressure in chronic thromboembolic pulmonary hypertension. J Am Coll Cardiol 2002; 40: 318-324.

117. Krüger S, Haage $\mathrm{P}$, Hoffmann $\mathrm{R}$, et al. Diagnosis of pulmonary arterial hypertension and pulmonary embolism with magnetic resonance angiography. Chest 2001; 120: 1556-1561.

118. Kuriyama K, Gamsu G, Stern RG, Cann CE, Herfkens RJ, Brundage BH. CT-determined pulmonary 
artery diameters in predicting pulmonary hypertension. Invest Radiol 1984; 19: 16-22.

119. Tardivon AA, Mousseaux E, Brenot F, et al. Quantification of hemodynamics in primary pulmonary hypertension with magnetic resonance imaging. Am J Respir Crit Care Med 1994; 150: 1075-1080.

120. Bergin CJ, Hauschildt J, Rios G, Belezzuoli EV, Huynh T, Channick RN. Accuracy of MR angiography compared with radionuclide scanning in identifying the cause of pulmonary arterial hypertension. Am J Roentgenol 1997; 168: 1549-1555.

121. Rich S, Chomka E, Hasara L, et al. The prevalence of pulmonary hypertension in the United States. Adult population estimates obtained from measurements of chest roentgenograms from the NHANES II survey. Chest 1989; 96: 236-241.

122. Fukuchi K, Hayashida K, Nakanishi $\mathrm{N}$, et al. Quantitative analysis of lung perfusion in patients with primary pulmonary hypertension. J Nucl Med 2002; 43: 757-761.

123. Gomez A, Bialostozky D, Zajarias A, et al. Right ventricular ischemia in patients with primary pulmonary hypertension. J Am Coll Cardiol 2001; 38: $1137-$ 1142.

124. Gayed I, Boccalandro F, Fang B, Podoloff D. New method for calculating right ventricular ejection fraction using gated myocardial perfusion studies. Clin Nucl Med 2002; 27: 334-338.

125. Bossone E, Paciocco G, Larussi D, et al. The prognostic role of the ECG in primary pulmonary hypertension. Chest 2002; 121: 513-518.

126. Adnot S, Chabrier PE, Andrivet $\mathrm{P}$, et al. Atrial natriuretic peptide concentrations and pulmonary hemodynamics in patients with pulmonary artery hypertension. Am Rev Respir Dis 1987; 136: 951-956.

127. Nagaya N, Nishikimi T, Uematsu M, et al. Plasma brain natriuretic peptide as a prognostic indicator in patients with primary pulmonary hypertension. Circulation 2000; 102: 865-870.

128. Wiedmann R, Ghofrani HA, Weismann N, et al. Atrial natriuretic peptide in severe primary and nonprimary pulmonary hypertension. Response to Iloprost inhalation. J Am Coll Cardiol 2001; 38: 1130-1136.

129. Rich S, Levy P. Characteristics of surviving and nonsurviving patients with primary pulmonary hypertension. Am J Med 1984; 76: 573-578.

130. Glanville AR, Burke CM, Robin TJ. Primary pulmonary hypertension. length of survival in patients referred for heart-lung transplantation. Chest 1987; 91: 675-681.

131. Kanemoto N. Natural history of pulmonary hemodynamics in primary pulmonary hypertension. Am Heart $J$ 1987; 114: 407-413.

132. Fuster V, Steele PM, Edwards WD, Gersh BJ, McGoon MD, Frye RL. Primary pulmonary hypertension: natural history and importance of thrombosis. Circulation 1984; 70: 580-587.

133. Eysmann SB, Palevsky HI, Reichek N, Hackney K, Douglas PS. Two-dimensional and Dopplerechocardiographic and cardiac catheterization correlates of survival in primary pulmonary hypertension. Circulation 1989; 80: 353-360.

134. Raymond RJ, Hinderliter AL, Willis $\mathrm{PW}$, et al. Echocardiographic predictors of adverse outcomes in primary pulmonary hypertension. $\mathrm{J}$ Am Coll Cardiol 2002; 39: 1214-1219.

135. Sitbon $\mathrm{O}$, Humbert $\mathrm{M}$, Nunes $\mathrm{H}$, et al. Long-term intravenous epoprostenol infusions in primary pulmonary hypertension. Prognostic factors of survival. $\mathrm{J} \mathrm{Am}$ Coll Cardiol 2002; 40: 780-788.

136. Oswald-Mammoser M, Weitzenblum E, Quoix E, et al. Prognostic factors in COPD patients receiving longterm oxygen therapy. Importance of pulmonary artery pressure. Chest 1995; 107: 1193-1198.

137. Kessler R, Faller M, Fourgaut G, Mennecier B, Weitzenblum E. Predictive factors of hospitalization for acute exacerbation in a series of 64 patients with chronic obstructive pulmonary disease. Am J Respir Crit Care Med 1999; 159: 158-164.

138. Hopkins WE, Ochoa LL, Richardson GW, Trulowk EP. Comparison of the hemodynamics and survival of adults with severe primary pulmonary hypertension or Eisenmenger syndrome. $J$ Heart Lung Transplant 1996; 15: 100-105.

139. Hopkins WE, Waggoner AD. Severe pulmonary hypertension without right ventricular failure: the unique hearts of patients with Eisenmenger syndrome. Am J Cardiol 2002; 89: 34-38.

140. Ghio S, Gavazzi A, Campana C, et al. Independent and additive prognostic value of right ventricular systolic function in patients with chronic heart failure. J Am Coll Cardiol 2001; 37: 183-188.

141. Cappola TP, Felker M, Kao WHL, Hare JM, Baughman KL, Kasper EK. Pulmonary hypertension and risk of death in cardiomyopathy. Patients with myocarditis are a higher risk. Circulation 2002; 105: $1663-1668$. 